\title{
Impact of aerosol microphysical properties on mass scattering cross sections
}

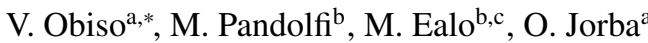 \\ ${ }^{a}$ Earth Sciences Department, Barcelona Supercomputing Center (BSC-ES), c/ Jordi Girona 29, 08034, Barcelona, Spain. \\ ${ }^{b}$ Institute of Environmental Assessment and Water Research (IDAEA-CSIC), c/ Jordi Girona 18-26, 08034, Barcelona, Spain. \\ ${ }^{c}$ Department of Astronomy and Meteorology, Faculty of Physics, University of Barcelona, c/ Martí i Franquès 1, 08028, Barcelona, Spain.
}

\begin{abstract}
We assessed the sensitivity of simulated mass scattering cross sections $\left(\alpha_{\lambda}^{s c a}\right)$ of three aerosol species to perturbed particle microphysical properties and derived constraints on these microphysical properties, suitable for the north-western Mediterranean basin, from a comparison between code calculations and observations. In detail, we calculated $\alpha_{\lambda}^{s c a}$ of mineral dust, organic carbon and sulfate at three wavelengths in the visible range $\left(\lambda_{1}=0,450 \mu m ; \lambda_{2}=0,525 \mu m ; \lambda_{3}=0,635 \mu m\right)$ with a T-matrix optical code, considering $\pm 20 \%$ perturbations on size distribution, refractive index and mass density (respect to reference values mainly taken from the OPAC database), and spheroids with two different axial ratios as shape perturbations (reference shape: sphere). Then, we compared the simulation results with a set of observed $\alpha_{\lambda}^{s c a}$ of mineral dust, aged organics and ammonium sulfate sources, available at the same three wavelengths of the code calculations. These observations, provided by the Institute of Environmental Assessment and Water Research (IDAEA-CSIC), have been derived through Multilinear Regression (MLR) analysis from measurements of aerosol mass concentrations and optical properties, collected during a 4-year campaign at the Montseny regional background station (Spain) and representative of the north-western Mediterranean basin. We observed quite different impacts of the microphysical perturbations on $\alpha_{\lambda}^{s c a}$ values and spectral dependence for different aerosol species, due mainly to the different size of the particles respect to the visible wavelengths. Moreover, by means of a compatibility test on best fit parameters, we constrained the mineral dust log-normal size distribution to a geometric radius and a standard deviation of $r_{g}=3,583 \cdot 10^{-1} \mu m$ and $\sigma_{g}=1,600$, respectively (effective radius: $r_{\text {eff }}=6,221 \cdot 10^{-1} \mu \mathrm{m}$ ), the organic carbon log-normal size distribution parameters to $r_{g}=2,544 \cdot 10^{-2} \mu \mathrm{m}$ and $\sigma_{g}=1,760\left(r_{e f f}=5,656 \cdot 10^{-2} \mu m\right)$, the organic carbon real refractive index to $n_{R}=(1,576 ; 1,576 ; 1,576)$ at $\left(\lambda_{1} ; \lambda_{2} ; \lambda_{3}\right)$, the sulfate $\log$-normal size distribution parameters to $r_{g}=8,340 \cdot 10^{-2} \mu \mathrm{m}$ and $\sigma_{g}=1,624\left(r_{\text {eff }}=1,501 \cdot 10^{-1} \mu \mathrm{m}\right)$ and the sulfate real refractive index to $n_{R}=(1,547 ; 1,545 ; 1,543)$ at $\left(\lambda_{1} ; \lambda_{2} ; \lambda_{3}\right)$, in the north-western Mediterranean basin. Regarding the other perturbed microphysical properties, we found the reference prescriptions to be suitable for this geographical region, according to the same analysis procedure.
\end{abstract}

\section{Keywords}

1. Aerosol microphysical properties

2. Aerosol optical properties

3. Aerosol scattering spectral analysis

4. Aerosol source scattering observations

5. Constraints on particle microphysical properties

\section{Introduction}

Atmospheric aerosols can scatter and absorb electromagnetic radiation, causing a redistribution of the radiative energy in the atmosphere [Boucher et al., 2013]. Even if the model parameterization of this Aerosol-Radiation Interaction (ARI) have extremely improved over the last two decades [Myhre et al., 2013a], the ARI radiative forcing still contributes to dominate the uncertainty associated with the anthropogenic contribution to the climate change [Myhre et al., 2013b]. Also the role of the natural aerosols in affecting the Earth's radiative balance through ARI is poorly constrained [Rap et al., 2013]. The

${ }^{*}$ Corresponding author at: Earth Sciences Department, Barcelona Supercomputing Center (BSC-ES), c/ Jordi Girona 29, 08034, Barcelona, Spain.

Email address: vincenzo.obiso@bsc.es (V. Obiso)
ARI parameterization mainly consists in the characterization of the aerosol optical properties. Yu et al. [2006] and Zhang et al. [2016] pointed out that large uncertainties in the estimates of the ARI radiative effects still exist and that they are mainly caused (among other factors) by errors in the estimation of the aerosol optical properties. The optical properties in turn depend, in addition to radiation wavelength and aerosol mass concentration, on the microphysical properties of the particles, such as size distribution, refractive index, mixing state, shape, hygroscopicity and mass density [Boucher et al., 2013; Hand and Malm, 2007]. The uncertainty affecting the optical properties, indeed, is caused above all by an incomplete knowledge concerning the microphysical properties of the particles [Yu et al., 2006]. Hence, different assumptions on the microphysical properties can affect the calculation of the optical properties and so the assessments of the ARI radiative effects. For this reason, we consider a study on the relationship between microphysical and optical properties a recommendable first step to better parameterize the ARI in the atmospheric models.

In this paper we present a numerical experiment carried out in order to assess the impact of perturbed aerosol microphysical properties on values and spectral dependence of simulated mass 
scattering cross sections $\left(\alpha_{\lambda}^{s c a}\left[m^{2} / g\right]\right.$ : scattering coefficients per unit mass concentration). Significant perturbations on the particle microphysical properties aimed to reproduce the great uncertainty by which these are affected. Moreover, we provide constraints on these microphysical assumptions (suitable for the north-western Mediterranean basin), found by achieving the best agreement (compatibility of best fit parameters) between simulated and observed $\alpha_{\lambda}^{\text {sca }}$. The $\alpha_{\lambda}^{\text {sca }}$ simulations have been performed with a T-Matrix code, for mineral dust, organic carbon and sulfate, at three wavelengths in the visible range $\left(\lambda_{1}=0,450 \mu m ; \lambda_{2}=0,525 \mu m ; \lambda_{3}=0,635 \mu m\right)$. Reference values for size distribution, refractive index and mass density of each aerosol species have been perturbed of $\pm 20 \%$ and spheroids with two different axial ratios have been considered as shape perturbations. The observation dataset used has been provided by the Institute of Environmental Assessment and Water Research (IDAEA-CSIC). From measurements of aerosol mass concentrations and optical properties, collected at the Montseny regional background station (Spain) during a 4-year campaign, $\alpha_{\lambda}^{s c a}$ have been derived through Multilinear Regression (MLR) applied to aerosol sources (mineral dust, aged organics and ammonium sulfate) at three visible wavelengths (the same we selected for the code calculations). These data, even if representative of the north-western Mediterranean basin, result compatible with the quite extended range of estimates available in literature [Hand and Malm, 2007].

In Section 2, a detailed description of optical code and observations used is given; in Sections 3 and 4, experiment setup and data analysis, respectively, are explained; in Sections 5 and 6 , the experiment results are presented and discussed, respectively; in Section 7, summary and future works are presented.

\section{Methodology}

For our experiment we used an optical code and a set of observations of aerosol $\alpha_{\lambda}^{s c a}$, which we present in this section. An optical code is able to calculate scattering and absorption of radiation either by a mono-disperse (only one size) or polydisperse particles (different distributed sizes), starting from their microphysical properties. Many techniques of calculation, underlying to different physical approximations, exist, each one with its skills and limitations [Mishchenko et al., 2002].

\subsection{T-matrix code}

The T-matrix method is a powerful exact technique for computing light scattering by non-spherical particles [Mishchenko and Travis, 1998]. The incident and the scattered electromagnetic fields are expanded in series of vector spherical wave functions, with the relation between the expansion coefficients established through the T-matrix [Mishchenko et al., 2004]. The T-matrix is determined by the scatterer microphysical properties and, for a given incident field, allows calculating the scattered field.

For this work, the T-matrix code by Mishchenko and Travis [1998] has been used. It allows calculating integrated optical properties of poly-disperse, randomly oriented, rotationally symmetric, homogeneous particles. Two versions of the same code have been used, double-precision and extended-precision, in order to solve calculation convergence issues caused by considering high size parameters $x$ (defined as $x=2 \pi r / \lambda$ : ratio between the particle radius $r$ and the radiation wavelength $\lambda$ ) for strongly non-spherical particles. This code appeared the most adequate for this experiment because of its flexibility and precision in calculating bulk optical properties to be compared with the observations.

\subsection{Observations}

We used a set of observed aerosol $\alpha_{\lambda}^{\text {sca }}$ provided by the IDAEA-CSIC. Pandolfi et al. [2011] collected measurements of aerosol $P M_{10}$ mass concentrations (gravimetric masses from $24 \mathrm{~h}$ filters) and optical properties (scattering coefficients with Nephelometer AURORA 3000, Ecotech), in the period 20102014, at the Montseny regional background station (middle altitude emplacement within the Montseny Natural Park, Spain: $41^{\circ} 46^{\prime} 45,63 " N-02^{\circ} 21^{\prime} 28,92 " E ; 720 m$ a.s.1.). The frequency of the gravimetric samples was $3 / 4$ samples per week $(24 \mathrm{~h})$. The Nephelometer worked continuously with a raw resolution of 5 minutes, it was calibrated 3/4 times per year (using $\mathrm{CO}_{2}$ as span gas) and zero adjusts were performed every $24 \mathrm{~h}$. The Montseny station is a GAW ${ }^{1}$ and ACTRIS ${ }^{2}$ station, therefore instrument calibration and measurements were performed following the network standards and procedures (the data are continuously provided to these networks). The annual mean Relative Humidity (RH) at the sampling site is $\sim 75 \% \pm 20 \%$ (personal communication from Marco Pandolfi). In order to reduce the effects of hygroscopicity on the scattering properties of the particles, a RH threshold of $40 \%$ was set in the sampling cell by using a processor-controlled automatic heater inside the Nephelometer. This experimental procedure, which follows the ACTRIS standards, has been applied elsewhere (i.e. Pereira et al. [2011]; Anderson and Ogren [1998]). Hence, during the study period, the mean $\mathrm{RH}$ in the Nephelometer sampling cell was $\sim 28 \% \pm 12 \%$ [Pandolfi et al., 2011].

From these data, Ealo et al. [ults] derived $\alpha_{\lambda}^{s c a}$ at 3 visible wavelengths $\left(\lambda_{1}=0,450 \mu \mathrm{m} ; \lambda_{2}=0,525 \mu \mathrm{m} ; \lambda_{3}=0,635 \mu \mathrm{m}\right)$ through MLR analysis (Nephelometer data were averaged over the gravimetric sampling time before performing the MLR). The MLR method has been previously used in order to calculate $\alpha_{\lambda}^{s c a}$ of chemical species, by considering the species concentrations (externally mixed) as dependent variables, the measured scattering coefficients as independent variables and the $\alpha_{\lambda}^{s c a}$ as regression coefficients [White and Macias, 1987; Hand and Malm, 2007]. But in Ealo et al. [ults], the MLR has been performed considering sources of aerosols [Pandolfi et al., 2016] detected in the $P M_{10}$ mass chemical speciated data [Querol et al., 2009] through the application of the Positive Matrix Factorization (PMF) model [Paatero, 1997] (a system able to recognize correlations in the variability of the mass concentrations of two or more different aerosol species and so to associate the

\footnotetext{
${ }^{1}$ www.wmo.int/pages/prog/arep/gaw/gaw_home_en.html

${ }^{2}$ www.actris.eu
} 
correlated species with the same aerosol source). Hence, in this MLR the source contributions to $P M_{10}$ obtained from the PMF model were considered as dependent variables, instead of the chemical species concentrations, and so a unique $\alpha_{\lambda}^{s c a}$ has been obtained for each source detected at the Montseny station. It is important to note that this different approach is based on a different assumption on the mixing state of the atmospheric aerosols [White and Macias, 1987]. In other words, the sources are supposed to be aerosol mixtures, dominated by a low number of species (from which they take the name) but including minor internally mixed species. Thus, the resulting regression coefficients in the MLR applied to sources represent $\alpha_{\lambda}^{s c a}$ of internally mixed aerosols (at least in a certain degree). Note that considering sources instead of externally mixed species in the MLR also reduces some collinearity issues and makes the regression coefficients less sensitive to data uncertainties [Hand and Malm, 2006].

Seven sources were detected using the PMF model at the Montseny station but in our work we used only three of them: mineral dust (traced by typical crustal elements such as $A l, C a$, $T i, R b, S r$ ), aged organics (traced mainly by organic carbon, with maxima in summer indicating a prevalent biogenic origin but with a significant contribution from biomass burning) and ammonium sulfate (secondary inorganic source traced mainly by $\mathrm{SO}_{4}^{2-}$ and $\mathrm{NH}_{4}^{+}$) [Pandolfi et al., 2016]. The biomass burning contribution to the aged organics source at Montseny has been evaluated to be $\sim 30 \%$ [Ealo et al., 2016] and it includes a certain amount of absorbing brown carbon and black carbon as minor species. Independent sources traced by other important species, such as black carbon or sea salt, have not been considered for this work for the following reasons. Black carbon contributes to $<2 \%$ to the $P M_{10}$ mass at Montseny [Pandolfi et al., 2011] and so in this particular geographical area it is not a dominant species. In fact, it has not been detected as an isolated source by the PMF model but it is taken into account as a minor species in the aged organics source. Moreover, black carbon is mainly an absorbing species, being its contribution to the scattering negligible (in this work we analyzed only aerosol scattering properties). For sea salt, the PMF model detected the aged marine source (traced by $\mathrm{Na}$ and $\mathrm{Cl}$ and enriched in nitrates). However, as shown in Pandolfi et al. [2016], the contribution of this source to $P M_{10}$ mass concentration is quite low at Montseny $(\sim 10 \%)$, compared to the contributions of the mineral dust $(\sim 17 \%)$, aged organics $(\sim 23 \%)$ and ammonium sulfate $(\sim 24 \%)$ sources. At Barcelona, for example, the absolute contribution to $P M_{10}$ of the aged marine source was found more than 3 times higher compared to its contribution at Montseny [Pandolfi et al., 2016]. As a consequence, the MLR provided $\alpha_{\lambda}^{s c a}$ for the aged marine source with a relative error of $~ 30 \%$, value abundantly above the threshold of $15 \%$ (at $\lambda=0,525 \mu \mathrm{m}$ ) which we fixed in order to be able to derive significantly strict constraints on the microphysical properties of the modelled aerosol species. The observed $\alpha_{\lambda}^{s c a}$ for the three sources used in this work are reported in Table 1.

As mentioned above, with the MLR applied to sources, a possible internal mixing between dominant and minor species is taken into account. This more realistic representation of the atmospheric aerosols allowed us to tune the reference microphysical properties for the modelled species (derived from very general literature prescriptions) taking into account, in an indirect and simple way, also the effects of the internally mixed minor species on the ARI of the dominant species. Note that parameterizing explicitly this source internal mixing for the code calculations would be an unfeasible way due to the high variability in both the number and the mixing percentage of the minor species in the sources. Moreover, for our experiment we needed $\alpha_{\lambda}^{s c a}$ at more than one wavelength, since we analyzed not only the value at one wavelength but also the spectral dependence of the $\alpha_{\lambda}^{s c a}$. In literature many experimental estimates of aerosol $\alpha_{\lambda}^{\text {sca }}$ are available: a survey of approximately 60 ground-based estimates produced since 1990 for different aerosols, in different geographical locations, under a variety of monitoring conditions and with 4 different techniques used, has been published in Hand and Malm [2007]. However, it has to be noted that all these estimates are given at one wavelength (mainly $\sim 0,550 \mu \mathrm{m}$ ) and furthermore refer to aerosol species, not sources. Hence, given the lack of experimental $\alpha_{\lambda}^{s c a}$ estimates at more than one wavelength and given that the novelty of presenting $\alpha_{\lambda}^{s c a}$ of aerosol sources was able to enrich our analysis, this dataset appeared the most adequate for our experiment. The data we used can be considered representative of the regional background of the north-western Mediterranean basin. It is true that in order to properly represent a "regional level", data from more than one station should be used. A high number of stations, indeed, measure for example gaseous compounds or $P M$ mass concentrations at regional level in the north-western Mediterranean. However, in this region only the Montseny station provides long term $P M_{10}$ mass chemical speciated data, needed to derive the observed $\alpha_{\lambda}^{s c a}$ of aerosol sources used in this work. Despite this, it is plenty of publications demonstrating that the Montseny station is representative of the typical regional background conditions in the north-western Mediterranean basin (i.e. Pandolfi et al. [2014]; Pérez et al. [2008]; Pey et al. [2009]). Finally, note that the $\alpha_{\lambda}^{s c a}$ experimental estimates we used, even if local data, fall within the quite extended range of experimental estimates available in literature, as we can note if comparing them with the values reported in Hand and Malm [2007] (Table 3: MLR method).

\section{Experiment setup}

In order to characterize the reference aerosol species (dry and homogeneous), four particle microphysical properties have been taken into account: size distribution (geometric radius $r_{g}$ [ $\mu m$ ] and standard deviation $\sigma_{g}$ [unitless]), refractive index (real $n_{R}$ and imaginary $n_{I}$ parts [unitless]), mass density $\left(\rho\left[\mathrm{kg} / \mathrm{m}^{3}\right]\right)$ and shape (axial ratio $\chi$ [unitless]). We defined the reference microphysical properties following the aerosol parameterization used in the NMMB-MONARCH model (formerly known as NMMB/BSC-CTM) [Jorba et al., 2012; Pérez et al., 2011; Spada et al., 2013], which in turn is based on the OPAC database [Hess et al., 1998], but with some deviations. Mineral dust has been associated with the mineral (accumulation mode) OPAC 
component (MIAM), except for geometric radius, taken from Shettle [1984], and mass density, taken from Nickovic et al. [2001] (the NMMB-MONARCH model considers different values of dust mass density for sub-micron and super-micron bins, so for our bulk mineral dust we derived a weighted mean of the original values). Organic carbon has been associated with the water-soluble OPAC component (WASO), except for standard deviation, taken from Chin et al. [2002], and imaginary refractive index. In order to take into account the biomass burning contribution (including absorbing brown carbon) to the aged organics source, indeed, the imaginary refractive index for organic carbon has been modified, in this work, respect to the values used in the NMMB-MONARCH model. In particular, the original reference values have been corrected by means of a weighted mean with modern estimates from Kirchstetter et al. [2004] and Shamjad et al. [2016], suitable for biomass burning organic aerosols. Finally, sulfate has been associated with the sulfate-droplets OPAC component (SUSO). In Table 2 the reference microphysical properties for all the species considered are reported.

In the aerosol modelling community, many important models use OPAC prescriptions (fully or partially) in their particle parameterization [Baklanov et al., 2014]: for example GOCART [Chin et al., 2000, 2002, 2009] (which considers also the same OPAC component-species association used in this work), WRF-CMAQ [Pleim et al., 2008; Mathur et al., 2010; Wong et al., 2012], MEMO/MARS-aero [Moussiopoulos et al., 2012; Halmer et al., 2010], RegCM4-Chem [Zakey et al., 2006; Solmon et al., 2006; Shalaby et al., 2012] and RAMS/ICLAMS [Kallos et al., 2009; Solomos et al., 2011]. Nevertheless, we do not consider the reference properties used as optimal values for the aerosol microphysics. We decided to start our analysis from these reference properties, indeed, in order to test and potentially improve them. In other words, our main goal was not to start from "correct" reference values but, starting from widely used values, to find "correct" constraints for them. For this purpose, we considered significant perturbations spanning very large ranges of values for the reference microphysical properties. They were supposed, indeed, to represent the great uncertainty affecting these properties and above all to cover suitable values for them. On the other hand, note that for the sensitivity study the "goodness" of the reference values is not a critical requirement.

After defining the reference microphysical properties, we performed calculations of integrated $\alpha_{\lambda}^{s c a}$ of mineral dust, organic carbon and sulfate, through the formula derived from the Equation (2) of Hand and Malm [2007] with substituting the mass size distribution to the number size distribution:

$$
\alpha_{\lambda}^{s c a}=\frac{\beta_{\lambda}^{s c a}}{M}=\frac{3<Q_{\lambda}^{s c a}>_{s}}{4 \rho r_{e f f}}
$$

where, in addition to the already defined symbols, $\beta_{\lambda}^{s c a}$ is the aerosol scattering coefficient, $<Q_{\lambda}^{s c a}>_{s}$ the mean scattering efficiency (average performed over the projected surface size distribution), $M$ the mass concentration, and $r_{\text {eff }}$ the effective radius (defined as $r_{e f f}=<r^{3}>/<r^{2}>$ with the averages performed over the normalized number size distribution [Hansen and Travis, 1974]). The calculations have been performed at three wavelengths in the visible range $\left(\lambda_{1}=0,450 \mu m ; \lambda_{2}=\right.$ $\left.0,525 \mu \mathrm{m} ; \lambda_{3}=0,635 \mu \mathrm{m}\right)$ : the wavelengths at which the observations were available. Then, in order to generate variability in the microphysical assumptions for the particles, we gave as inputs to the T-Matrix code the reference microphysical properties independently perturbed: this means that when a property was perturbed the other ones were not. In particular, for each aerosol species, we considered perturbations of $\pm 20 \%$ on size distribution (separately for $r_{g}$ and $\sigma_{g}$ ), refractive index (separately for $n_{R}$ and $n_{I}$ ) and mass density $\rho$; as perturbations for the spherical shape we considered two types of spheroid: moderate and extreme, averaging for each $\chi$ the oblate and the prolate options. In Table 2 also perturbed microphysical properties and correspondent case acronyms for all the species considered are reported.

\section{Data analysis}

We compared simulated and observed $\alpha_{\lambda}^{s c a}$ associating mineral dust with the mineral dust source, organic carbon with the aged organics source and sulfate with the ammonium sulfate source. At first, we evaluated the sensitivity of $\alpha_{\lambda}^{s c a}$ values and spectral dependence to the different perturbed microphysical properties. Regarding the $\alpha_{\lambda}^{s c a}$ values, for each species and microphysical property we estimated the extent of the variability range (maximum minus minimum value generated by the perturbations) of the simulated value at $\lambda_{2}=0,525 \mu \mathrm{m}$ (intermediate wavelength of the spectral range of the experiment) respect to the uncertainty (two times the standard error) affecting the observed value at the same wavelength:

$$
V_{\text {ratio }}=\frac{\Delta \alpha_{0,525}^{\text {sca,sim }}}{\Delta \alpha_{0,525}^{\text {sca,obs }}}
$$

The perturbation impact has been considered significant only when $V_{\text {ratio }}>1$ (namely when the simulated range exceeds the error band of the observed value). Regarding the $\alpha_{\lambda}^{s c a}$ spectral dependence, instead, we estimated the extent of the variability range (maximum minus minimum value) of the spectral dependence slope $s$ (from logarithmic linear fits, as explained below) of the simulated values respect to the uncertainty (two times the fit standard error) affecting the slope of the observed values:

$$
S_{\text {ratio }}=\frac{\Delta s^{\text {sim }}}{\Delta s^{o b s}}
$$

Again the perturbation impact has been considered significant only when $S_{\text {ratio }}>1$.

The spectral dependence slopes have been derived by performing linear fits of the logarithmic spectral dependence of both simulated and observed $\alpha_{\lambda}^{s c a}$, taking into account the measurement errors as weights for the observation fits. The linearity of $\log \left(\alpha_{\lambda}^{s c a}\right)$ versus $\log (\lambda)$ is a first approximation of the more suitable second order polynomial dependence, describing a spectral variation of the Ångström exponent [Kaskaoutis et al., 2007]. Moreover its range of validity depends on the spectral position 
of the maximum of the $\alpha_{\lambda}^{s c a}$ (affected by the size distribution and the refractive index of the particles), since in correspondence of the maximum the $\alpha_{\lambda}^{s c a}$ spectral dependence trend must change even in the logarithmic scale and so the linearity hypothesis appears to be inapplicable. The $\alpha_{\lambda}^{s c a}$ spectral maximum originates from the resonances between diffracted and transmitted radiation arising in single-particle scattering events. The integration over whatever size distribution of a particle ensemble, indeed, smooths out the secondary resonances but preserves the principal maximum, which only spreads out [Hansen and Travis, 1974; Mishchenko et al., 2002]. The spectral position of the $\alpha_{\lambda}^{s c a}$ maximum moves together with the $r_{e f f}$ of the particles (for poly-disperse particles the $r_{\text {eff }}$ can be considered the representative size of the ensemble, regarding the scattering processes [Hansen and Travis, 1974]). For low values of $\sigma_{g}(\lesssim 1,6)$ the maximum occurs for $\Delta \Phi_{e f f}=2 x_{e f f}\left(n_{R}-1\right) \sim 4,1$, being $\Delta \Phi_{\text {eff }}$ the phase shift of an electromagnetic wave passing through an effective particle of size parameter $x_{\text {eff }}$ and real refractive index $n_{R}$ [Hansen and Travis, 1974], and for $n_{R} \sim 1,33$ it approximately corresponds to $x_{e f f} \sim 2 \pi$, that is $\lambda \sim r_{e f f}$. With increasing $\sigma_{g}(\gtrsim 1,6)$ the maximum slightly moves towards higher values of $x_{e f f}$ (fixed $n_{R}$ ), that is $\lambda \lesssim r_{e f f}$, but always $r_{e f f}$ is an approximative indicator of its spectral position. On the other hand, with increasing $n_{R}$ the maximum moves towards lower $x_{\text {eff }}$ (fixed $\sigma_{g}$ ), that is $\lambda \gtrsim r_{\text {eff }}$. Hence, the effects of increasing $\sigma_{g}$ and $n_{R}$ more or less balance each other, so for example for $n_{R} \sim 1,5$ and $\sigma_{g} \sim 2$ again the maximum approximately corresponds to $\lambda \sim r_{\text {eff }}$. The position of the maximum is very important in this work to analyze the $\alpha_{\lambda}^{s c a}$ spectral characteristics. However, in all the cases considered in this work, the condition of linearity of the logarithmic spectral dependence of the $\alpha_{\lambda}^{s c a}$ has been considered satisfied, although with a variable degree of accuracy, except for two size distribution cases ( $\mathrm{mm}$ and $\mathrm{rm}$ ) and three refractive index cases ( $\mathrm{mm}, \mathrm{mr}$ and $\mathrm{mp}$ ) of mineral dust (following the case nomenclature explained in Table 2 ). For these cases the $\alpha_{\lambda}^{s c a}$ maximum falls within the spectral range of the experiment and therefore they have been excluded from the linear fit analysis (although shown in the graphs). For the logarithmic linear fits we used the following formula:

$$
\log \left(\alpha_{\lambda}^{s c a}\right)=s \cdot \log \left(\frac{\lambda}{0,525}\right)+q
$$

where $s$ is the mentioned slope, opposite of the $\alpha_{\lambda}^{s c a}$ Angström exponent, and $q=\log \left(\alpha_{0,525}^{s c a}\right)$ (fit estimate).

In order to complete the comparison analysis and to constrain the perturbed microphysical properties, then, we performed a compatibility test on the best fit parameters $s$ and $q$ :

$$
x_{\text {test }}=\frac{\left|x_{\text {sim }}-x_{\text {obs }}\right|}{\sqrt{\sigma_{x, \text { sim }}^{2}+\sigma_{x, o b s}^{2}}}
$$

where $x$ is the current parameter ( $s$ or $q$ ) and $\sigma_{x}$ its standard deviation (the least squares method fit errors are assumed to be one standard deviation errors of normally distributed variables). The test has been performed, for each aerosol species, on the best fit parameters of all the perturbed simulations respect to those of the correspondent observations. We defined the value of $x_{\text {test }}=1,65$ as compatibility threshold for the single parameters (corresponding to a confidence interval of 90\%) and considered, then, two fits fully compatible when the total test score $t_{\text {test }}=s_{\text {test }}+q_{\text {test }}<1,65$, partially compatible when $1,65<t_{\text {test }}<3,00$ and not compatible when $t_{\text {test }}>3,00$.

\section{Results}

In Table 3 the compatibility test values for all the species and perturbation cases are reported. The following discussion about the constraints on the particle microphysical properties is based on this table.

\subsection{Mineral dust}

The size distribution perturbations (see Figure 1-a for the related spectral $\alpha_{\lambda}^{s c a}$ ) do not have any significant effect on the $\alpha_{\lambda}^{s c a}$ spectral dependence $\left(S_{\text {ratio }}=0,24\right)$ while strongly affect the values of $\alpha_{\lambda}^{\text {sca }}\left(V_{\text {ratio }}=3,8\right)$, in the spectral range of the experiment (this clarification will be omitted but keeps true in the rest of the current analysis discussion). The $\alpha_{\lambda}^{\text {sca }}$ spectral maximum of mineral dust lies at longer wavelengths than those of the visible range (positive logarithmic linear spectral dependence slope in the visible range). With increasing the effective radius, the $\alpha_{\lambda}^{s c a}$ maximum decreases, because of the inverse dependence of $\alpha_{\lambda}^{s c a}$ on $r_{e f f}$, and moves towards longer wavelengths. This causes the $\alpha_{\lambda}^{\text {sca }}$ values to decrease at all the considered wavelengths (due to both the maximum drop and shift) but leaves nearly unaffected the $\alpha_{\lambda}^{s c a}$ spectral dependence. Looking at Table 3 (size distribution rows): the reference case ref results $s$-compatible but $q$-incompatible; all the perturbed simulations reach the $s$-compatibility similarly to the reference case (best $s_{\text {test }}$ from $p m: 0,72$ ) but now a simulation is $q$-compatible (best $q_{\text {test }}$ from $p m$ : 0,02) with the observations; the best total score is from $p m$ ( $t_{\text {test }}=0,74$ : full fit compatibility). The strong impact of the size distribution perturbations on the $\alpha_{\lambda}^{s c a}$ values makes the $p m$ case fully fit compatible with the observations and this allows us to strictly constrain, in the northwestern Mediterranean basin, the mineral dust size distribution parameters to the values $r_{g}=3,583 \cdot 10^{-1} \mu m$ and $\sigma_{g}=1,600$ $\left(r_{\text {eff }}=6,221 \cdot 10^{-1} \mu \mathrm{m}\right)$.

The refractive index perturbations (see Figure 1-b for the related spectral $\alpha_{\lambda}^{s c a}$ ) show a significant influence neither on the $\alpha_{\lambda}^{s c a}$ spectral dependence $\left(S_{\text {ratio }}=0,11\right)$ nor on the values of $\alpha_{\lambda}^{\text {sca }}\left(V_{\text {ratio }}=0,30\right)$. Fixed a size distribution, increasing the real part of the refractive index causes the $\alpha_{\lambda}^{s c a}$ spectral maximum to grow and to move towards longer wavelengths (while increasing the imaginary part just attenuates the whole scattering values). Due to the dust $\alpha_{\lambda}^{s c a}$ maximum position, these effects balance each other and so leave both $\alpha_{\lambda}^{\text {sca }}$ values and spectral dependence nearly unaffected by the perturbations. Looking at Table 3 (refractive index rows): similarly to the reference case, all the perturbed simulations reach the $s$-compatibility (best $s_{\text {test }}$ from $p p: 0,89$ ) and no simulations the $q$-compatibility (best $q_{\text {test }}$ from $r m: 8,46$ ) with the observations; the best total score is from $r m\left(t_{\text {test }}=9,58\right.$ : fit incompatibility). Since the impact of the refractive index perturbations 
on both $\alpha_{\lambda}^{s c a}$ values and spectral dependence is negligible, no fit compatibility is reached and so it is not possible to get any kind of constraint on this microphysical property for mineral dust.

The mass density perturbations (see Figure 1-c for the related spectral $\alpha_{\lambda}^{s c a}$ ) leave unaffected the $\alpha_{\lambda}^{s c a}$ spectral dependence $\left(S_{\text {ratio }}=0,0087\right)$ while have a not negligible impact on the $\alpha_{\lambda}^{\text {sca }}$ values $\left(V_{\text {ratio }}=1,3\right)$. Since the mass density does not affect the calculation of the scattering efficiency $\left\langle Q_{\lambda}^{s c a}>_{s}\right.$, increasing its value does not cause any shift of the $\alpha_{\lambda}^{s c a}$ spectral maximum but only a drop. Hence, the $\alpha_{\lambda}^{s c a}$ values decrease ( $\alpha_{\lambda}^{s c a}$ inversely depends on the mass density) but the $\alpha_{\lambda}^{s c a}$ spectral dependence remains unaffected. Looking at Table 3 (mass density rows): similarly to the reference case, all the perturbed simulations result $s$-compatible (best $s_{\text {test }}$ from $m$ : 0,99) and no simulations $q$-compatible (best $q_{\text {test }}$ from $m$ : 5,26 ) with the observations; the $m$ case has the best total score $\left(t_{\text {test }}=6,25\right.$ : fit incompatibility). The impact of the mass density perturbations on the $\alpha_{\lambda}^{s c a}$ values, even if significant, does not produce any fit compatibility and so it does not allow us to strictly constrain this microphysical property for mineral dust.

The shape perturbations (see Figure 1-d for the related spectral $\alpha_{\lambda}^{s c a}$ ) have a significant impact neither on the $\alpha_{\lambda}^{s c a}$ spectral dependence $\left(S_{\text {ratio }}=0,073\right)$ nor on the $\alpha_{\lambda}^{\text {sca }}$ values $\left(V_{\text {ratio }}=\right.$ 0, 072). Looking at Table 3 (shape rows): similarly to the reference case, all the perturbed simulations result $s$-compatible (best $s_{\text {test }}$ from ref: 1,00$)$ and no simulations $q$-compatible (best $q_{\text {test }}$ from ext: 8,50) with the observations; the best total score is from the ext case ( $t_{\text {test }}=9,65$ : fit incompatibility). Since the impact of the shape perturbations on both $\alpha_{\lambda}^{s c a}$ values and spectral dependence is negligible, no fit compatibility is achieved and so no constraints on this microphysical property for mineral dust can be derived.

\subsection{Organic carbon}

The size distribution perturbations (see Figure 2-a for the related spectral $\alpha_{\lambda}^{s c a}$ ) affect significantly both the $\alpha_{\lambda}^{s c a}$ spectral dependence $\left(S_{\text {ratio }}=2,0\right)$ and the values of $\alpha_{\lambda}^{\text {sca }}\left(V_{\text {ratio }}=6,0\right)$. The $\alpha_{\lambda}^{s c a}$ spectral maximum of organic carbon lies at shorter wavelengths than those of the visible range (negative logarithmic linear spectral dependence slope in the visible range). Increasing the effective radius causes the $\alpha_{\lambda}^{s c a}$ maximum to get closer to the experiment spectral range (the opposite of the dust case) and to decrease, due to the inverse dependence of $\alpha_{\lambda}^{s c a}$ on $r_{e f f}$. For this reason, the $\alpha_{\lambda}^{s c a}$ values at first increase, because closer and closer to the maximum, but then start to decrease because the maximum drop becomes dominant. The $\alpha_{\lambda}^{\text {sca }}$ spectral dependence trend keeps decreasing, although moderately variable. Looking at Table 3 (size distribution rows): the reference case ref results $s$-compatible but not $q$-compatible; all the perturbed simulations show different $s$-compatibilities (best $s_{\text {test }}$ from pm: 0,73$)$ but similarly to the reference case are not $q$-compatible (best $q_{\text {test }}$ from pm: 1,82) with the observations; the best total score is from $p m\left(t_{t e s t}=2,55\right.$ : partial fit compatibility). The significant impact of the size distribution perturbations on both $\alpha_{\lambda}^{s c a}$ values and spectral dependence makes the $p m$ case partially fit compatible with the observations, with a perfect coherence between the best fit parameters: $p m$ has the best $s_{\text {test }}$ and the best $q_{\text {test }}$, being though the $q_{\text {test }}$ value above the single parameter compatibility threshold. This partial fit compatibility allows us to constrain, in the north-western Mediterranean basin, the organic carbon size distribution parameters to the values $r_{g}=2,544 \cdot 10^{-2} \mu \mathrm{m}$ and $\sigma_{g}=1,760$ $\left(r_{e f f}=5,656 \cdot 10^{-2} \mu m\right)$. However, the not full fit compatibility suggests that some adjustments derived from other microphysical properties could improve the agreement between code calculations and observations (see Section 6).

The refractive index perturbations (see Figure 2-b for the related spectral $\alpha_{\lambda}^{s c a}$ ) show a negligible impact on the $\alpha_{\lambda}^{s c a}$ spectral dependence $\left(S_{\text {ratio }}=0,53\right)$ but a strong impact on the $\alpha_{\lambda}^{s c a}$ values (being the influence of the real part dominant) $\left(V_{\text {ratio }}=\right.$ 9,7 ). Due to the organic carbon $\alpha_{\lambda}^{s c a}$ maximum position, the effects of increasing the real refractive index (growth and shift of the $\alpha_{\lambda}^{s c a}$ maximum towards longer wavelengths) now do not balance each other and cause the $\alpha_{\lambda}^{\text {sca }}$ values to increase, leaving though the $\alpha_{\lambda}^{\text {sca }}$ spectral dependence nearly unaffected. Looking at Table 3 (refractive index rows): similarly to the reference case, all the perturbed simulations are $s$-compatible (best $s_{\text {test }}$ from $\mathrm{mm}$ : 0,54$)$ and no simulations $q$-compatible (best $q_{\text {test }}$ from $m m$ : 7,16) with the observations; the best total score is from $m m$ ( $t_{\text {test }}=7,70$ : fit incompatibility). The significant impact of the refractive index perturbations on the $\alpha_{\lambda}^{s c a}$ values is not able to generate any fit compatibility and so it does not allow us to derive any kind of constraint on this microphysical property for organic carbon.

The mass density perturbations (see Figure 2-c for the related spectral $\alpha_{\lambda}^{s c a}$ ) leave the $\alpha_{\lambda}^{s c a}$ spectral dependence unaffected $\left(S_{\text {ratio }}=0,000036\right)$ while have a relevant impact on the $\alpha_{\lambda}^{s c a}$ values $\left(V_{\text {ratio }}=2,8\right)$. The effects of changing the mass density is the same as for mineral dust, so the $\alpha_{\lambda}^{s c a}$ values decrease with increasing the mass density value but the $\alpha_{\lambda}^{s c a}$ spectral dependence remains unaffected. Looking at Table 3 (mass density rows): similarly to the reference case, all the perturbed simulations show $s$-compatibility (best $s_{\text {test }}$ from $r e f, m$ and $p$ : 1,15 ) and $q$-incompatibility (best $q_{\text {test }}$ from $p: 5,38$ ) with the observations; the best total score is from the $p$ case $\left(t_{\text {test }}=6,53\right.$ : fit incompatibility). The impact of the mass density perturbations on the $\alpha_{\lambda}^{s c a}$ values is relevant but not able to produce any fit compatibility and so not useful to strictly constrain this microphysical property for organic carbon.

The shape perturbations (see Figure 2-d for the related spectral $\left.\alpha_{\lambda}^{s c a}\right)$ do not affect the $\alpha_{\lambda}^{s c a}$ spectral dependence $\left(S_{\text {ratio }}=\right.$ $0,063)$ but, differently from the dust case, have a relevant impact on the $\alpha_{\lambda}^{s c a}$ values $\left(V_{\text {ratio }}=1,3\right)$. Looking at Table 3 (shape rows): similarly to the reference case, all the perturbed simulations reach the $s$-compatibility (best $s_{\text {test }}$ from ext: 1,03) and no simulations the $q$-compatibility (best $q_{\text {test }}$ from ext: 4,98 ) with the observations; the best total score is from the ext case $\left(t_{\text {test }}=6,01\right.$ : fit incompatibility). The relevant impact of the shape perturbations on the $\alpha_{\lambda}^{\text {sca }}$ values does not allow us to strictly constrain this microphysical property for organic carbon, because no fit compatibility is achieved. 


\subsection{Sulfate}

The size distribution perturbations (see Figure 3-a for the related spectral $\alpha_{\lambda}^{s c a}$ ) affect significantly both the $\alpha_{\lambda}^{s c a}$ spectral dependence $\left(S_{\text {ratio }}=5,2\right)$ and the values of $\alpha_{\lambda}^{s c a}\left(V_{\text {ratio }}=3,3\right)$. The $\alpha_{\lambda}^{s c a}$ spectral maximum of sulfate lies at shorter wavelengths than those of the visible range (negative logarithmic linear spectral dependence slope in the visible range). Increasing the effective radius has for sulfate the same effects as for organic carbon on the spectral maximum of the $\alpha_{\lambda}^{s c a}$, so again the $\alpha_{\lambda}^{s c a}$ values at first increase and then start to decrease because the drop of the $\alpha_{\lambda}^{s c a}$ maximum becomes dominant respect to its getting closer to the experiment spectral range. The $\alpha_{\lambda}^{s c a}$ spectral dependence trend keeps decreasing although significantly variable. Looking at Table 3 (size distribution rows): the reference case ref reaches neither the $s$-compatibility nor the $q$-compatibility; all the perturbed simulations show different $s$-compatibilities (best $s_{\text {test }}$ from pm: 0,30$)$ but similarly to the reference case are not $q$-compatible (best $q_{\text {test }}$ from ref: 10,77 ) with the observations; the best total score is from $p m\left(t_{\text {test }}=12,32\right.$ : fit incompatibility). The strong impact of the size distribution perturbations on both $\alpha_{\lambda}^{s c a}$ values and spectral dependence is not able to generate any fit compatibility and so to provide any strict constraint on this microphysical property for sulfate. Moreover, the best $s_{\text {test }}$ (from pm: compatibility value) and the best $q_{\text {test }}$ (from ref: incompatibility value) come from different cases. Hence, there seems to be an incoherence between the two best fit parameters (both significantly affected by the perturbations). This suggests that more microphysical properties for sulfate have to be tuned for the code to reproduce the experimental data (see Section 6). The refractive index perturbations (see Figure 3-b for the related spectral $\alpha_{\lambda}^{s c a}$ ) show a strong impact on both the $\alpha_{\lambda}^{s c a}$ spectral dependence $\left(S_{\text {ratio }}=3,0\right)$ and the $\alpha_{\lambda}^{\text {sca }}$ values (being the influence of the imaginary part totally negligible, due to the very low values for sulfate) $\left(V_{\text {ratio }}=9,1\right)$. Due to the sulfate $\alpha_{\lambda}^{s c a}$ maximum position, again the unbalanced combined effects of increasing the real refractive index (growth and shift of the $\alpha_{\lambda}^{s c a}$ maximum towards longer wavelengths) cause the $\alpha_{\lambda}^{s c a}$ values to increase, but now affecting also the $\alpha_{\lambda}^{s c a}$ spectral dependence. Looking at Table 3 (refractive index rows): all the perturbed simulations show different $s$-compatibilities (best $s_{\text {test }}$ from $m m, m r$ and $m p$ : 0,20) and strongly different $q$-compatibilities (best $q_{\text {test }}$ from $p m, p r$ and $p p$ : 0,84 ) with the observations; the best total scores are from $p m, p r$ and $p p$ $\left(t_{\text {test }}=6,88\right.$ : fit incompatibility). The impact of the refractive index perturbations on both $\alpha_{\lambda}^{\text {sca }}$ values and spectral dependence is relevant but again not able to generate any fit compatibility and so useless to strictly constrain this microphysical property for sulfate. Moreover, again the best $s_{\text {test }}$ (from $m m, m r$ and $m p$ : compatibility value) and the best $q_{\text {test }}$ (from $p m, p r$ and $p p$ : compatibility value) come from different cases, showing a second incoherence between the two best fit parameters (both significantly affected by the perturbations). This confirms that more microphysical properties for sulfate have to be simultaneously changed in order to achieve a better agreement between code results and experimental data (see Section 6).

The mass density perturbations (see Figure 3-c for the re- lated spectral $\alpha_{\lambda}^{s c a}$ ) leave the $\alpha_{\lambda}^{s c a}$ spectral dependence unaffected $\left(S_{\text {ratio }}=0,0020\right)$ and affect only the $\alpha_{\lambda}^{\text {sca }}$ values $\left(V_{\text {ratio }}=\right.$ $3,2)$. The effects of changing the mass density is the same as for the other aerosols, so the $\alpha_{\lambda}^{s c a}$ values decrease with increasing the mass density value, but the $\alpha_{\lambda}^{s c a}$ spectral dependence is not affected. Looking at Table 3 (mass density rows): similarly to the reference case, no perturbed simulations result $s$-compatible (best $s_{\text {test }}$ from ref, $m$ and $p$ : 4,05) nor $q$-compatible (best $q_{\text {test }}$ from $m: 3,24$ ) with the observations; the best total score is from the $m$ case $\left(t_{\text {test }}=7,29\right.$ : fit incompatibility). The not negligible impact of the mass density perturbations on the $\alpha_{\lambda}^{s c a}$ values is not able to generate any fit compatibility and so it makes impossible to strictly constrain this microphysical property for sulfate.

The shape perturbations (see Figure 3-d for the related spectral $\alpha_{\lambda}^{s c a}$ ) do not affect significantly the $\alpha_{\lambda}^{s c a}$ spectral dependence $\left(S_{\text {ratio }}=0,30\right)$ but have a relevant impact on the $\alpha_{\lambda}^{s c a}$ values $\left(V_{\text {ratio }}=1,2\right)$. Looking at Table 3 (shape rows): similarly to the reference case, all the perturbed simulations show both $s$ incompatibility (best $s_{\text {test }}$ from ext: 3,49 ) and $q$-incompatibility (best $q_{\text {test }}$ from ref: 10,77 ) with the observations; the best total score is from the ref case $\left(t_{\text {test }}=14,82\right.$ : fit incompatibility). Even if the impact of the shape perturbations on the $\alpha_{\lambda}^{s c a}$ values is not negligible, it is not useful to strictly constrain this microphysical property for sulfate, since it does not generate any fit compatibility.

\section{Discussion}

We found that the mineral dust $\alpha_{\lambda}^{s c a}$ values are only affected by the size distribution and, with a lower impact, by the mass density perturbations. On the other hand, no microphysical properties seem to have any impact on the $\alpha_{\lambda}^{s c a}$ spectral dependence. So, it appears that, due mainly to the size of the particles bigger than the visible wavelengths, the dust $\alpha_{\lambda}^{s c a}$ are quite stable respect to the microphysical perturbations (in the spectral range of the experiment). The size distribution case $\mathrm{pm}$ reaches full fit compatibility with the observations $\left(t_{\text {test }}=0,74\right)$ and this allows us to strictly constrain the mineral dust size distribution. Other minor adjustments on the $\alpha_{\lambda}^{s c a}$ values could come only from the mass density perturbations, but they are useless in this case since the size distribution case $p m$ has the best $q_{\text {test }}$ (and also the best $s_{\text {test }}$ even if the variability of the $s_{\text {test }}$ values due to the size distribution perturbations has been found quantitatively insignificant). So, there seems to be a perfect coherence between the two best fit parameters. Hence, for mineral dust we confirm that, in the north-western Mediterranean basin, the prescriptions derived from our analysis are (being the refractive index values relative to $\lambda_{1}, \lambda_{2}$ and $\lambda_{3}$, respectively):

$$
\begin{aligned}
& \text { Size distribution: } r_{g}=3,583 \cdot 10^{-1} \mu \mathrm{m} \\
& \sigma_{g}=1,600 \\
& r_{\text {eff }}=6,221 \cdot 10^{-1} \mu \mathrm{m}
\end{aligned}
$$


Refractive index: $n_{R}=(1,530 ; 1,530 ; 1,530) \quad$ (reference)

$$
n_{I}=(8,500 ; 6,650 ; 4,500) \cdot 10^{-3} \quad \text { (reference) }
$$

Mass density: $\rho=2,506 \cdot 10^{3} \mathrm{~kg} / \mathrm{m}^{3} \quad$ (reference)

$$
\text { Shape: } \chi=1,000 \quad \text { (reference) }
$$

Hence, it seems that smaller dust particles (higher geometric radius but lower standard deviation) than the reference ones reach the north-western Mediterranean basin. Regarding the other perturbed microphysical properties, the reference prescriptions seem to describe well the mineral dust source in this geographical area.

The organic carbon $\alpha_{\lambda}^{s c a}$ values are affected mainly by refractive index (real part), size distribution and, with a lower impact, by mass density and shape perturbations. The $\alpha_{\lambda}^{s c a}$ spectral dependence, instead, is significantly affected only by the size distribution perturbations. So, the organic carbon $\alpha_{\lambda}^{s c a}$ appear less stable than the mineral dust ones respect to the microphysical perturbations, due mainly to the size of the particles smaller than the visible wavelengths. The size distribution case $\mathrm{pm}$ reaches partial fit compatibility with the observations $\left(t_{\text {test }}=2,55\right)$ and this allows us to constrain the organic carbon size distribution. However, despite the perfect coherence between the best fit parameters, the $\alpha_{\lambda}^{s c a}$ values of the size distribution case pm result a little "too low" respect to the observations. Hence, in order to achieve the full fit compatibility, since the refractive index (real part) has the strongest impact on the $\alpha_{\lambda}^{s c a}$ values, we tried to apply an adequate real refractive index increase to the size distribution case $\mathrm{pm}$. We found an optimal real refractive index increase to be of $3 \%$ respect to the reference values. In this composite case (the violet line in Figure 2a), both the $s$-compatibility and the $q$-compatibility of the size distribution case $p m$ improve $\left(s_{\text {test }}=0,70\right.$ and $\left.q_{\text {test }}=0,13\right)$ and the full fit compatibility is achieved $\left(t_{\text {test }}=0,83\right)$. This result allows us to strictly constrain simultaneously size distribution and real refractive index for organic carbon. Hence, for organic carbon, in the north-western Mediterranean basin, the prescriptions derived from our analysis are (being the refractive index values relative to $\lambda_{1}, \lambda_{2}$ and $\lambda_{3}$, respectively):

$$
\begin{aligned}
& \text { Size distribution: } r_{g}=2,544 \cdot 10^{-2} \mu \mathrm{m} \\
& \sigma_{g}=1,760 \\
& r_{e f f}=5,656 \cdot 10^{-2} \mu \mathrm{m} \\
& \text { Refractive index: } n_{R}=(1,576 ; 1,576 ; 1,576) \\
& n_{I}=(1,730 ; 1,250 ; 0,696) \cdot 10^{-2} \quad \text { (reference) } \\
& \text { Mass density: } \rho=1,800 \cdot 10^{3} \mathrm{~kg} / \mathrm{m}^{3} \quad \text { (reference) } \\
& \text { Shape: } \chi=1,000 \quad \text { (reference) }
\end{aligned}
$$

Hence, smaller organic carbon particles (higher geometric radius but lower standard deviation) and with a slightly higher real refractive index (in the visible range) than the reference particles seem to be representative of the north-western Mediterranean basin. Regarding mass density and shape instead, the reference prescriptions seem to describe well the aged organics source in this geographical area.

The sulfate $\alpha_{\lambda}^{s c a}$ values are mainly affected by the refractive index (real part) and, with a lower impact, by size distribution, mass density and shape perturbations. On the other hand, the $\alpha_{\lambda}^{s c a}$ spectral dependence is only affected by size distribution and refractive index perturbations. So, it seems that the sulfate $\alpha_{\lambda}^{s c a}$ are the most unstable respect to the microphysical perturbations, due to the particle size approximately comparable with the visible wavelengths. For sulfate, no perturbation cases reach any fit compatibility with the observations. The size distribution case $p m$ has the best $s_{\text {test }}$ while ref has the best $q_{\text {test }}$. On the other hand, the refractive index case $m r$ has the best $s_{\text {test }}$ but $p r$ has the best $q_{\text {test }}$ (considering only the real part of the refractive index since the imaginary part has not any influence). Hence, in order to solve these incoherences and to achieve full fit compatibility, since the refractive index (real part) has the strongest impact on the $\alpha_{\lambda}^{s c a}$ values, we tried to consider the size distribution case $\mathrm{pm}$ with an increased real refractive index. We found an optimal real refractive index increase to be of $8 \%$ respect to the reference values. In this composite case (the violet line in Figure 3-a), the $s$-compatibility of the $\mathrm{pm}$ size distribution case (best value) gets a little worse but remains very good $\left(s_{\text {test }}=0,76\right)$, while the $q$-compatibility improves significantly $\left(q_{\text {test }}=0,30\right)$. So, applying this small real refractive index perturbation to the size distribution case $\mathrm{pm}$ produces full fit compatibility $\left(t_{\text {test }}=1,06\right)$, allowing us to constrain simultaneously size distribution and refractive index also for sulfate. Hence, for sulfate, in the north-western Mediterranean basin, the prescriptions derived from our analysis are (being the refractive index values relative to $\lambda_{1}, \lambda_{2}$ and $\lambda_{3}$, respectively):

$$
\begin{aligned}
& \text { Size distribution: } r_{g}=8,340 \cdot 10^{-2} \mu \mathrm{m} \\
& \sigma_{g}=1,624 \\
& r_{\text {eff }}=1,501 \cdot 10^{-1} \mu \mathrm{m} \\
& n_{I}=(1,000 ; 1,000 ; 1,610) \cdot 10^{-8} \quad \text { (reference) } \\
& \text { Shape: } \chi=1,000 \quad \text { (reference) }
\end{aligned}
$$

Hence, smaller sulfate particles (higher geometric radius but lower standard deviation) and with a higher real refractive index (in the visible range) than the reference particles seem to be representative of the north-western Mediterranean basin. Regarding mass density and shape, again the reference prescriptions appear to be adequate to describe the ammonium sulfate source in this geographical area.

\section{Summary}

Through a comparison between code simulations and observations, we assessed the sensitivity of simulated $\alpha_{\lambda}^{\text {sca }}$ (values and spectral dependence) of mineral dust, organic carbon and sulfate to significantly perturbed microphysical properties (size distribution, refractive index, mass density and shape) and also constrained these properties in the north-western Mediterranean basin. We observed that the impact of the microphysical assumptions on the scattering properties mainly depends on the 
size of the particles. The species with mean size smaller than (organic carbon) or almost comparable with (sulfate) the visible wavelengths (spectral range of this experiment) appear, indeed, to be more unstable. We performed the code simulations using reference microphysical properties derived from very general literature prescriptions, but widely used in the aerosol modelling community. We applied significant perturbations on these reference properties, indeed, in order to reproduce the great uncertainty affecting them. As observations, we used $\alpha_{\lambda}^{s c a}$ of aerosol sources detected at the Montseny regional background station. The aerosol sources are supposed to be a more realistic representation of the aerosols in atmosphere and allowed us to take into account the effects of minor internally mixed species on the ARI of the dominant species (which are the modelled species). In the future, we will carry out a second numerical experiment in order to study the impact of the particle microphysical perturbations on the atmospheric ARI radiative effects. Then, we will incorporate our microphysical prescriptions in the aerosol module of the NMMB-MONARCH model, in order to evaluate the impact of the ARI radiative effect variations, due to particle microphysical perturbations, on meteorology and climate.

\section{Vitae}

Vincenzo Obiso studied Theoretical Physics at the University of Rome (Italy). He is a Ph.D. student at the Earth Sciences Department of the Barcelona Supercomputing Center (BSC-ES, Barcelona, Spain) since 2013. His research plan focuses on the implementation of the dynamic aerosol-radiation interaction within the NMMB-MONARCH model, an online integrated meteorologychemistry model under development at the BSC-ES, and on the evaluation of its impact on the meteorological forecasts.

Marco Pandolfi is researcher at the Institute of Environmental Assessment and Water Research of the Spanish Research Council (IDAEA-CSIC, Barcelona, Spain). He has more than 15 years research experience on physical, optical and chemical properties of atmospheric aerosols. He is the scientific coordinator of the IDAEA research line aiming at studying the link existing between air quality and climate. He authored and co-authored more than 70 peer-reviewed papers in international journals and over 100 communications to international conferences.

Marina Ealo studied Environmental Sciences and Meteorology. She is a Ph.D. student at the Spanish Research Council (IDAEA-CSIC, Barcelona, Spain) since 2014. Her thesis is focused on studying the optical and chemical properties of the atmospheric aerosols and their impact on air quality and climate. She also manages the Montsec sampling station integrated in the Global Atmosphere Watch (GAW) program.

Oriol Jorba has a Ph.D. in Environmental Engineering (2005). His research activities have included high resolution mesoscale meteorology, air quality and development of online meteorology-chemistry models. In 2005, he was enrolled as researcher at the Earth Sciences Department of the Barcelona Supercomputing Center (BSC-ES, Barcelona, Spain) and in 2008 moved to the Atmospheric Modelling Group Manager position. Now he is senior researcher of the Atmospheric Composition group. He held a research position at the University of California Irvine (USA) in 2011 and at the NASA Goddard Institute for Space Studies (USA) in 2013. He has co-authored more than 50 papers in international scientific journals and over 100 communications to international conferences.

\section{Funding sources \& Acknowledgements}

This work has been funded by the Spanish Ministry of Economy and Competitiveness [grant: CGL2013-46736-R] and by the ACTRIS Research Infrastructure Project of the European Union's Horizon 2020 research and innovation programme [grant agreement: No. 654169]. Further support has been provided by the Severo Ochoa Program, awarded by the Spanish Government [grant: SEV-2011-00067]. This work was also supported by the MINECO (Spanish Ministry of Economy and Competitiveness), the MAGRAMA (Spanish Ministry of Agriculture, Food and Environment) and FEDER funds under the PRISMA project [grant: CGL2012-39623-C02/00]. Further fundings have been provided by the European Union's Horizon 2020 research and innovation programme [grant agreement: No. 654109]. Vincenzo Obiso is funded by the Spanish Ministry of Economy and Competitiveness ['FPI-SO' grant: SVP2013-067953]. Marco Pandolfi is funded by the Spanish Ministry of Economy and Competitiveness ['Ramón y Cajal' grant: RYC-2013-14036].

We thank Noemi Pérez for providing the PM chemical speciated data for the Montseny station and the developers of the T-Matrix code for making it freely available.

\section{References}

Anderson, T. L. and Ogren, J. A. (1998). Determining Aerosol Radiative Properties Using the TSI 3563 Integrating Nephelometer. Aerosol Sci. Tech., 29:57-69.

Baklanov, A., Schlünzen, K., Suppan, P., Baldasano, J. M., Brunner, D., Aksoyoglu, S., Carmichael, G., Douros, J., Flemming, J., Forkel, R., Galmarini, S., Gauss, M., Grell, G., Hirtl, M., Joffre, S., Jorba, O., Kaas, E., Kaasik, M., Kallos, G., Kong, X., Korsholm, U., Kurganskiy, A., Kushta, J., Lohmann, U., Mahura, A., Manders-Groot, A., Maurizi, A., Moussiopoulos, N., Rao, S. T., Savage, N., Seigneur, C., Sokhi, R. S., Solazzo, E., Solomos, S., Sørensen, B., Tsegas, G., Vignati, E., Vogel, B., and Zhang, Y. (2014). Online coupled regional meteorology chemistry models in Europe: current status and prospects. Atmos. Chem. Phys., 14:317-398.

Boucher, O., Randall, D., Artaxo, P., Bretherton, C., Feingold, G., Forster, P., Kerminen, V.-M., Kondo, Y., Liao, H., Lohmann, U., Rasch, P., Satheesh, S. K., Sherwood, S., Stevens, B., and Zhang, X. Y. (2013). Clouds and Aerosols. In Stocker, T. F., Qin, D., Plattner, G.-K., Tignor, M., Allen, S. K., Boschung, J., Nauels, A., Xia, Y., Bex, V., and Midgley, P. M., editors, Climate Change 2013: The Physical Science Basis. Contribution of Working Group I to the Fifth Assessment Report of the Intergovernmental Panel on Climate Change. Cambridge University Press, Cambridge, United Kingdom and New York, NY, USA.

Chin, M., Diehl, T., Dubovik, O., Eck, T. F., Holben, B. N., Sinyuk, A., and Streets, D. G. (2009). Light absorption by pollution, dust, and biomass burning aerosols: a global model study and evaluation with AERONET measurements. Ann. Geophys., 27:3439-3464.

Chin, M., Ginoux, P., Kinne, S., Torres, O., Holben, B. N., Duncan, B. N., Martin, R. V., Logan, J. A., Higurashi, A., and Nakajima, T. (2002). Tropospheric Aerosol Optical Thickness from the GOCART Model and Comparisons with Satellite and Sun Photometer Measurements. Journal of the Atmospheric Sciences, 59:461-483.

Chin, M., Rood, R. B., Lin, S.-J., Müller, J.-F., and Thompson, A. M. (2000). Atmospheric sulfur cycle simulated in the global model GOCART: Model description and global properties. J. Geophys. Res., 105(D20):2467124687.

Ealo, M., Alastuey, A., Pérez, N., Ripoll, A., Querol, X., and Pandolfi, M. (unpublished results). From air quality to climate; Impact of aerosol sources on optical properties at urban, regional and continental levels in the northwestern Mediterranean. Atmos. Chem. Phys., in preparation.

Ealo, M., Alastuey, A., Ripoll, A., Pérez, N., Minguillón, M. C., Querol, X., and Pandolfi, M. (2016). Detection of Saharan dust and biomass burning events using near-real-time intensive aerosol optical properties in the north-western Mediterranean. Atmos. Chem. Phys., 16:12567-12586.

Halmer, G., Douros, I., Tsegas, G., and Moussiopoulos, N. (2010). Using a coupled meteorological and chemical transport modelling scheme to evaluate the impact of the aerosol direct effect on pollutant concentration fields in Paris. In Proceedings of the 31th NATO/SPS International Technical Meeting on Air Pollution Modelling and its Application (ITM2010), Turin, Italy, 27 Sep.-1 Oct. 2010.

Hand, J. L. and Malm, W. C. (2006). Review of the IMPROVE Equation for Estimating Ambient Light Extinction Coefficients. Report Colorado State University - Appendix 2.

Hand, J. L. and Malm, W. C. (2007). Review of aerosol mass scattering efficiencies from groud-based measurements since 1990. J. Geophys. Res., 112, D16203. 
Hansen, J. E. and Travis, L. D. (1974). Light scattering in planetary atmospheres. Space Science Reviews, 16:527-610.

Hess, M., Köpke, P., and Schult, I. (1998). Optical Properties of Aerosols and Clouds: The Software Package OPAC. Bull. Am. Met. Soc., 79:831-844.

Jorba, O., Dabdub, D., Blaszczak-Boxe, C., Pérez, C., Janjic, Z., Baldasano, J. M., Spada, M., Badia, A., and Gonçalves, M. (2012). Potential significance of photoexcited NO2 on global air quality with the NMMB/BSC chemical transport model. J. Geophys. Res., 117, D13301.

Kallos, G., Solomos, S., and Kushta, J. (2009). Air quality - Meteorology Interaction Processes in the ICLAMS Modeling System. In 30th NATO/SPS International Technical Meeting on Air Pollution Modelling and its Application, San Francisco, 18-22 May 2009.

Kaskaoutis, D. G., Kambezidis, H. D., Hatzianastassiou, N., Kosmopoulos, P. G., and Badarinath, K. V. S. (2007). Aerosol climatology: dependence of the Ångström exponent on wavelength over four AERONET sites. Atmos. Chem. Phys. Discuss., 7:7347-7397.

Kirchstetter, T. W., Novakov, T., and Hobbs, P. V. (2004). Evidence that the spectral dependence of light absorption by aerosols is affected by organic carbon. J. Geophys. Res., 109, D21208.

Mathur, R., Pleim, J., Wong, D., Otte, T., Gilliam, R., Roselle, S., Young, J., Binkowski, F., and Xiu, A. (2010). The WRF-CMAQ integrated online modeling system: development, testing, and initial applications. In Air Pollution Modeling and Its Application XX, pages 155-159. Springer.

Mishchenko, M. I. and Travis, L. D. (1998). Capabilities and limitations of a current FORTRAN implementation of the T-matrix method for randomly oriented, rotationally symmetric scatterers. J. Quant. Spectrosc. Radiat. Transfer, 60:309-324.

Mishchenko, M. I., Travis, L. D., and Lacis, A. A. (2002). Scattering, Absorption and Emission of Light by Small Particles. Cambridge University Press, Cambridge, UK.

Mishchenko, M. I., Videen, G., Babenko, V. A., Khlebtsov, N. G., and Wriedt, T. (2004). T-matrix theory of electromagnetic scattering by particles and its applications: a comprehensive reference database. Journal of Quantitative Spectroscopy $\mathcal{E}$ Radiative Transfer, 88:357-406.

Moussiopoulos, N., Douros, I., Tsegas, G., Kleanthous, S., and Chourdakis, E. (2012). An air quality management system for policy support in Cyprus. Adv. Meteorol., 2012, 959280.

Myhre, G., Samset, B. H., Schulz, M., Balkanski, Y., Bauer, S., Berntsen, T. K., Bian, H., Bellouin, N., Chin, M., Diehl, T., Easter, R. C., Feichter, J., Ghan, S. J., Hauglustaine, D., Iversen, T., Kinne, S., Kirkevag, A., Lamarque, J.F., Lin, G., Liu, X., Lund, M. T., Luo, G., Ma, X., van Noije, T., Penner, J. E., Rasch, P. J., Ruiz, A., Seland, O., Skeie, R. B., Stier, P., Takemura, T., Tsigaridis, K., Wang, P., Wang, Z., Xu, L., Yu, H., Yu, F., Yoon, J.-H., Zhang, K., Zhang, H., and Zhou, C. (2013a). Radiative forcing of the direct aerosol effect from AeroCom Phase II simulations. Atmos. Chem. Phys., 13:1853-1877.

Myhre, G., Shindell, D., Bréon, F.-M., Collins, W., Fuglestvedt, J., Huang, J., Koch, D., Lamarque, J.-F., Lee, D., Mendoza, B., Nakajima, T., Robock, A., Stephens, G., Takemura, T., and Zhang, H. (2013b). Anthropogenic and Natural Radiative Forcing. In Stocker, T. F., Qin, D., Plattner, G.-K., Tignor, M., Allen, S. K., Boschung, J., Nauels, A., Xia, Y., Bex, V., and Midgley, P. M., editors, Climate Change 2013: The Physical Science Basis. Contribution of Working Group I to the Fifth Assessment Report of the Intergovernmental Panel on Climate Change. Cambridge University Press, Cambridge, United Kingdom and New York, NY, USA.

Nickovic, S., Kallos, G., Papadopoulos, A., and Kakaliagou, O. (2001). A model for prediction of desert dust cycle in the atmosphere. J. Geophys. Res., 106(D16):18113-18129.

Paatero, P. (1997). Least squares formulation of robust non-negative factor analysis. Chemometrics and Intelligent Laboratory Systems, 37:23-35.

Pandolfi, M., Alastuey, A., Pérez, N., Reche, C., Castro, I., Shatalov, V., and Querol, X. (2016). Trends analysis of PM source contributions and chemical tracers in NE Spain during 2004-2014: A multi-exponential approach. Atmos. Chem. Phys., 16:11787-11805.

Pandolfi, M., Cusack, M., Alastuey, A., and Querol, X. (2011). Variability of aerosol optical properties in the Western Mediterranean Basin. Atmos. Chem. Phys., 11:8189-8203.

Pandolfi, M., Querol, X., Alastuey, A., Jimenez, J. L., Jorba, O., Day, D., Ortega, A., Cubison, M. J., Comerón, A., Sicard, M., Mohr, C., Prévôt, A. S. H., Minguillón, M. C., Pey, J., Baldasano, J. M., Burkhart, K. F., Seco, R., Peñuelas, J., van Drooge, B. L., Artiñano, B., Di Marco, C., Nemitz, E.,
Schallhart, S., Metzger, A., Hansel, A., Lorente, J., Ng, S., Jayne, J., and Szidat, S. (2014). Effects of sources and meteorology on particulate matter in the Western Mediterranean Basin: An overview of the DAURE campaign. J. Geophys. Res. Atmos., 119:4978-5010.

Pereira, S. N., Wagner, F., and Silva, A. M. (2011). Seven years of measurements of aerosol scattering properties, near the surface, in the southwestern Iberia Peninsula. Atmos. Chem. Phys., 11:17-29.

Pérez, C., Haustein, K., Janjic, Z., Jorba, O., Huneeus, N., Baldasano, J. M., Black, T., Basart, S., Nickovic, S., Miller, R. L., Perlwitz, J. P., Schulz, M., and Thomson, M. (2011). Atmospheric dust modeling from meso to global scales with the online NMMB/BSC-Dust model - Part 1: Model description, annual simulations and evaluation. Atmos. Chem. Phys., 11:13001-13027.

Pérez, N., Pey, J., Castillo, S., Viana, M., Alastuey, A., and Querol, X. (2008). Interpretation of the variability of levels of regional background aerosols in the Western Mediterranean. Science of the Total Environment, 407:527-540.

Pey, J., Pérez, N., Castillo, S., Viana, M., Moreno, T., Pandolfi, M., LopezSebastian, J. M., Alastuey, A., and Querol, X. (2009). Geochemistry of regional background aerosols in the Western Mediterranean. Atmos. Res., 94:422-435.

Pleim, J., Young, J., Wong, D., Gilliam, R., Otte, T., and Mathur, R. (2008). Two-way coupled meteorology and air quality modeling. In Borrego, C. and Miranda, A. I., editors, Air Pollution Modeling and Its Application XIX, pages 496-504. Springer, the Netherlands. ISBN 978-1-4020-8452-2.

Querol, X., Alastuey, A., Pey, J., Cusack, M., Pérez, N., Mihalopoulos, N., Theodosi, C., Gerasopoulos, E., Kubilay, N., and Koçak, M. (2009). Variability in regional background aerosols within the Mediterranean. Atmos. Chem. Phys., 9:4575-4591.

Rap, A., Scott, C. E., Spracklen, D. V., Bellouin, N., Forster, P. M., Carslaw, K. S., Schmidt, A., and Mann, G. (2013). Natural aerosol direct and indirect radiative effects. Geophys. Res. Lett., 40:3297-3301.

Shalaby, A., Zakey, A. S., Tawfik, A. B., Solmon, F., Giorgi, F., Stordal, F., Sillman, S., Zaveri, R. A., and Steiner, A. L. (2012). Implementation and evaluation of online gas-phase chemistry within a regional climate model (RegCM-CHEM4). Geosci. Model Dev., 5:741-760.

Shamjad, P. M., Tripathi, S. N., Thamban, N. M., and Vreeland, H. (2016). Refractive Index and Absorption Attribution of Highly Absorbing Brown Carbon Aerosols from an Urban Indian City-Kanpur. Scientific Reports, 6, 37735.

Shettle, E. P. (1984). Optical and radiative properties of a desert aerosol model. In Fiocco, G., editor, IRS '84: Current Problems in Atmospheric Radiation, Proceedings of the International Radiation Symposium, Perugia, Italy, 21-28 Aug. 1984, pages 74-77. A. Deepak Publishing, Hampton, Virginia, USA.

Solmon, F., Giorgi, F., and Liousse, C. (2006). Aerosol modelling for regional climate studies: application to anthropogenic particles and evaluation over a European/African domain. Tellus B, 58:51-72.

Solomos, S., Kallos, G., Kushta, J., Astitha, M., Tremback, C., Nenes, A., and Levin, Z. (2011). An integrated modeling study on the effects of mineral dust and sea salt particles on clouds and precipitation. Atmos. Chem. Phys., 11:873-892.

Spada, M., Jorba, O., Pérez, C., Janjic, Z., and Baldasano, J. M. (2013). Modeling and evaluation of the global sea-salt aerosol distribution: sensitivity to size-resolved and sea-surface temperature dependent emission schemes. Atmos. Chem. Phys., 13:11735-11755.

White, W. H. and Macias, E. S. (1987). On measurement error and the empirical relationship of atmospheric extinction to aerosol composition in the nonurban West. In Bhardwaja, P. S., editor, Visibility Protection: Research and Policy Aspects, pages 783-794. Air Pollution Control Association (now A\&WMA), Pittsburgh.

Wong, D. C., Pleim, J., Mathur, R., Binkowski, F., Otte, T., Gilliam, R., Pouliot, G., Xiu, A., Young, J. O., and Kang, D. (2012). WRF-CMAQ two-way coupled system with aerosol feedback: software development and preliminary results. Geosci. Model Dev., 5:299-312.

Yu, H., Kaufman, Y. J., Chin, M., Feingold, G., Remer, L. A., Anderson, T. L., Balkanski, Y., Bellouin, N., Boucher, O., Christopher, S., DeCola, P., Kahn, R., Koch, D., Loeb, N., Reddy, M. S., Schulz, M., Takemura, T., and Zhou, M. (2006). A review of measurement-based assessments of the aerosol direct radiative effect and forcing. Atmos. Chem. Phys., 6:613-666.

Zakey, A. S., Solmon, F., and Giorgi, F. (2006). Implementation and testing of a desert dust module in a regional climate model. Atmos. Chem. Phys., 6:4687-4704. 
Zhang, Z., Meyer, K., Yu, H., Platnich, S., Colarco, P., Liu, Z., and Oreopoulos, L. (2016). Shortwave direct radiative effects of above-cloud aerosols over global oceans derived from 8 years of CALIOP and MODIS observations. Atmos. Chem. Phys., 16:2877-2900. 
Table 1: Observed $\alpha_{\lambda}^{s c a}$ of mineral dust (DU), aged organics (OC) and ammonium sulfate (SU) sources. The wavelengths are $\lambda_{1}=0,450 \mu m, \lambda_{2}=0,525 \mu m$ and $\lambda_{3}=0,635 \mu \mathrm{m}$.

\begin{tabular}{|c|c|c|c|c|}
\hline \multicolumn{2}{|c|}{ observations } & DU & OC & SU \\
\hline \multirow{2}{*}{$\alpha_{\lambda}^{\text {sca }}\left(\mathrm{m}^{2} / \mathrm{g}\right)$} & $\lambda_{1}$ & $1,046 \pm 0,130$ & $1,990 \pm 0,258$ & $5,860 \pm 0,256$ \\
& $\lambda_{2}$ & $1,262 \pm 0,106$ & $1,414 \pm 0,212$ & $4,508 \pm 0,210$ \\
& $\lambda_{3}$ & $1,429 \pm 0,096$ & $0,916 \pm 0,190$ & $3,092 \pm 0,188$ \\
\hline
\end{tabular}


Table 2: Reference (marked with a ${ }^{*}$ ) and perturbed microphysical properties, namely size distribution (SD), refractive index (RI), mass density (DN) and shape (SH), for mineral dust (DU), organic carbon (OC) and sulfate (SU), used for code simulations. The perturbation cases for size distribution, refractive index and mass density are named with the letters $m$ (i.e. minus : $-20 \%$ ), $r$ (i.e. reference) and $p$ (i.e. plus : $+20 \%$ ), applied separately to each parameter of the microphysical properties (for size distribution and refractive index the first letter refers to $r_{g}$ and $n_{R}$, while the second letter to $\sigma_{g}$ and $n_{I}$, respectively; for mass density the only one letter refers to $\rho$ ); the shape perturbation cases are indicated as ext (i.e. extreme spheroid) and mod (i.e. moderate spheroid), both cases including the oblate and the prolate options (the $\chi$ of the two options are reciprocals of each other). The cases $r r$ (for size distribution and refractive index), $r$ (for mass density) and $s p h$ (i.e. sphere, for shape) are omitted because they all coincide with the reference case, which we name $r e f$ for all the microphysical properties. The size distribution is log-normal and the size range $P M_{10}$ (starting from $0,001 \mu m$ ) for all the species. The three refractive index values in parentheses are relative to $\lambda_{1}=0,450 \mu \mathrm{m}, \lambda_{2}=0,525 \mu \mathrm{m}$ and $\lambda_{3}=0,635 \mu \mathrm{m}$, respectively. The axial ratio is defined as $\chi=a / b$, where $a$ is the axis perpendicular to the symmetry axis of the spheroid and $b$ the parallel one: the value $\chi=1$ indicates a sphere, while values $\chi>1$ and $\chi<1$ indicate oblate and prolate spheroids, respectively.

\begin{tabular}{|c|c|c|c|c|c|}
\hline & & cases & DU & OC & SU \\
\hline \multirow{9}{*}{ SD } & ref & $\begin{array}{l}r_{g}^{*}(\mu m) \\
\sigma_{g}^{*} \\
r_{e f f}^{*}(\mu m)\end{array}$ & $\begin{array}{l}2,986 \cdot 10^{-1} \\
2,000 \\
9,205 \cdot 10^{-1}\end{array}$ & $\begin{array}{l}2,120 \cdot 10^{-2} \\
2,200 \\
1,003 \cdot 10^{-1}\end{array}$ & $\begin{array}{l}6,950 \cdot 10^{-2} \\
2,030 \\
2,433 \cdot 10^{-1}\end{array}$ \\
\hline & $m m$ & $\begin{array}{l}r_{g}=0,8 \cdot r_{g}^{*}(\mu m) \\
\sigma_{g}=0,8 \cdot \sigma_{g}^{*} \\
r_{e f f}(\mu m)\end{array}$ & $\begin{array}{l}2,389 \cdot 10^{-1} \\
1,600 \\
4,150 \cdot 10^{-1}\end{array}$ & $\begin{array}{l}1,696 \cdot 10^{-2} \\
1,760 \\
3,771 \cdot 10^{-2}\end{array}$ & $\begin{array}{l}5,560 \cdot 10^{-2} \\
1,624 \\
1,001 \cdot 10^{-1}\end{array}$ \\
\hline & $m r$ & $\begin{array}{l}r_{g}=0,8 \cdot r_{g}^{*}(\mu m) \\
\sigma_{g}=1,0 \cdot \sigma_{g}^{*} \\
r_{e f f}(\mu m)\end{array}$ & $\begin{array}{l}2,389 \cdot 10^{-1} \\
2,000 \\
7,617 \cdot 10^{-1}\end{array}$ & $\begin{array}{l}1,696 \cdot 10^{-2} \\
2,200 \\
8,024 \cdot 10^{-2}\end{array}$ & $\begin{array}{l}5,560 \cdot 10^{-2} \\
2,030 \\
1,947 \cdot 10^{-1}\end{array}$ \\
\hline & $m p$ & $\begin{array}{l}r_{g}=0,8 \cdot r_{g}^{*}(\mu m) \\
\sigma_{g}=1,2 \cdot \sigma_{g}^{*} \\
r_{e f f}(\mu m)\end{array}$ & $\begin{array}{l}2,389 \cdot 10^{-1} \\
2,400 \\
1,150\end{array}$ & $\begin{array}{l}1,696 \cdot 10^{-2} \\
2,640 \\
1,782 \cdot 10^{-1}\end{array}$ & $\begin{array}{l}5,560 \cdot 10^{-2} \\
2,436 \\
3,965 \cdot 10^{-1}\end{array}$ \\
\hline & $r m$ & $\begin{array}{l}r_{g}=1,0 \cdot r_{g}^{*}(\mu m) \\
\sigma_{g}=0,8 \cdot \sigma_{g}^{*} \\
r_{e f f}(\mu m)\end{array}$ & $\begin{array}{l}2,986 \cdot 10^{-1} \\
1,600 \\
5,187 \cdot 10^{-1}\end{array}$ & $\begin{array}{l}2,120 \cdot 10^{-2} \\
1,760 \\
4,713 \cdot 10^{-2}\end{array}$ & $\begin{array}{l}6,950 \cdot 10^{-2} \\
1,624 \\
1,251 \cdot 10^{-1}\end{array}$ \\
\hline & $r p$ & $\begin{array}{l}r_{g}=1,0 \cdot r_{g}^{*}(\mu m) \\
\sigma_{g}=1,2 \cdot \sigma_{g}^{*} \\
r_{e f f}(\mu m)\end{array}$ & $\begin{array}{l}2,986 \cdot 10^{-1} \\
2,400 \\
1,293\end{array}$ & $\begin{array}{l}2,120 \cdot 10^{-2} \\
2,640 \\
2,219 \cdot 10^{-1}\end{array}$ & $\begin{array}{l}6,950 \cdot 10^{-2} \\
2,436 \\
4,890 \cdot 10^{-1}\end{array}$ \\
\hline & $p m$ & $\begin{array}{l}r_{g}=1,2 \cdot r_{g}^{*}(\mu m) \\
\sigma_{g}=0,8 \cdot \sigma_{g}^{*} \\
r_{e f f}(\mu m)\end{array}$ & $\begin{array}{l}3,583 \cdot 10^{-1} \\
1,600 \\
6,221 \cdot 10^{-1}\end{array}$ & $\begin{array}{l}2,544 \cdot 10^{-2} \\
1,760 \\
5,656 \cdot 10^{-2}\end{array}$ & $\begin{array}{l}8,340 \cdot 10^{-2} \\
1,624 \\
1,501 \cdot 10^{-1}\end{array}$ \\
\hline & $p r$ & $\begin{array}{l}r_{g}=1,2 \cdot r_{g}^{*}(\mu m) \\
\sigma_{g}=1,0 \cdot \sigma_{g}^{*} \\
r_{e f f}(\mu m)\end{array}$ & $\begin{array}{l}3,583 \cdot 10^{-1} \\
2,000 \\
1,061\end{array}$ & $\begin{array}{l}2,544 \cdot 10^{-2} \\
2,200 \\
1,204 \cdot 10^{-1}\end{array}$ & $\begin{array}{l}8,340 \cdot 10^{-2} \\
2,030 \\
2,919 \cdot 10^{-1}\end{array}$ \\
\hline & $p p$ & $\begin{array}{l}r_{g}=1,2 \cdot r_{g}^{*}(\mu m) \\
\sigma_{g}=1,2 \cdot \sigma_{g}^{*} \\
r_{e f f}(\mu m)\end{array}$ & $\begin{array}{l}3,583 \cdot 10^{-1} \\
2,400 \\
1,406\end{array}$ & $\begin{array}{l}2,544 \cdot 10^{-2} \\
2,640 \\
2,650 \cdot 10^{-1}\end{array}$ & $\begin{array}{l}8,340 \cdot 10^{-2} \\
2,436 \\
5,773 \cdot 10^{-1}\end{array}$ \\
\hline \multirow{9}{*}{$\mathbf{R I}$} & ref & $\begin{array}{l}n_{R}^{*} \\
n_{I}^{*}\end{array}$ & $\begin{array}{l}(1,530 ; 1,530 ; 1,530) \\
(8,500 ; 6,650 ; 4,500) \cdot 10^{-3}\end{array}$ & $\begin{array}{l}(1,530 ; 1,530 ; 1,530) \\
(1,730 ; 1,250 ; 0,696) \cdot 10^{-2}\end{array}$ & $\begin{array}{l}(1,432 ; 1,431 ; 1,429) \\
(1,000 ; 1,000 ; 1,610) \cdot 10^{-8}\end{array}$ \\
\hline & $m m$ & $\begin{array}{l}n_{R}=0,8 \cdot n_{R}^{*} \\
n_{I}=0,8 \cdot n_{I}^{*}\end{array}$ & $\begin{array}{l}(1,224 ; 1,224 ; 1,224) \\
(6,800 ; 5,320 ; 3,600) \cdot 10^{-3}\end{array}$ & $\begin{array}{l}(1,224 ; 1,224 ; 1,224) \\
(1,384 ; 1,000 ; 0,557) \cdot 10^{-2}\end{array}$ & $\begin{array}{l}(1,146 ; 1,145 ; 1,143) \\
(0,800 ; 0,800 ; 1,288) \cdot 10^{-8}\end{array}$ \\
\hline & $m r$ & $\begin{array}{l}n_{R}=0,8 \cdot n_{R}^{*} \\
n_{I}=1,0 \cdot n_{I}^{*}\end{array}$ & $\begin{array}{l}(1,224 ; 1,224 ; 1,224) \\
(8,500 ; 6,650 ; 4,500) \cdot 10^{-3}\end{array}$ & $\begin{array}{l}(1,224 ; 1,224 ; 1,224) \\
(1,730 ; 1,250 ; 0,696) \cdot 10^{-2}\end{array}$ & $\begin{array}{l}(1,146 ; 1,145 ; 1,143) \\
(1,000 ; 1,000 ; 1,610) \cdot 10^{-8}\end{array}$ \\
\hline & $m p$ & $\begin{array}{l}n_{R}=0,8 \cdot n_{R}^{*} \\
n_{I}=1,2 \cdot n_{I}^{*}\end{array}$ & $\begin{array}{l}(1,224 ; 1,224 ; 1,224) \\
(10,20 ; 7,980 ; 5,400) \cdot 10^{-3}\end{array}$ & $\begin{array}{l}(1,224 ; 1,224 ; 1,224) \\
(2,076 ; 1,500 ; 0,835) \cdot 10^{-2}\end{array}$ & $\begin{array}{l}(1,146 ; 1,145 ; 1,143) \\
(1,200 ; 1,200 ; 1,932) \cdot 10^{-8}\end{array}$ \\
\hline & $\mathrm{rm}$ & $\begin{array}{l}n_{R}=1,0 \cdot n_{R}^{*} \\
n_{I}=0,8 \cdot n_{I}^{*}\end{array}$ & $\begin{array}{l}(1,530 ; 1,530 ; 1,530) \\
(6,800 ; 5,320 ; 3,600) \cdot 10^{-3}\end{array}$ & $\begin{array}{l}(1,530 ; 1,530 ; 1,530) \\
(1,384 ; 1,000 ; 0,557) \cdot 10^{-2}\end{array}$ & $\begin{array}{l}(1,432 ; 1,431 ; 1,429) \\
(0,800 ; 0,800 ; 1,288) \cdot 10^{-8}\end{array}$ \\
\hline & $r p$ & $\begin{array}{l}n_{R}=1,0 \cdot n_{R}^{*} \\
n_{I}=1,2 \cdot n_{I}^{*}\end{array}$ & $\begin{array}{l}(1,530 ; 1,530 ; 1,530) \\
(10,20 ; 7,980 ; 5,400) \cdot 10^{-3}\end{array}$ & $\begin{array}{l}(1,530 ; 1,530 ; 1,530) \\
(2,076 ; 1,500 ; 0,835) \cdot 10^{-2}\end{array}$ & $\begin{array}{l}(1,432 ; 1,431 ; 1,429) \\
(1,200 ; 1,200 ; 1,932) \cdot 10^{-8}\end{array}$ \\
\hline & $p m$ & $\begin{array}{l}n_{R}=1,2 \cdot n_{R}^{*} \\
n_{I}=0,8 \cdot n_{I}^{*}\end{array}$ & $\begin{array}{l}(1,836 ; 1,836 ; 1,836) \\
(6,800 ; 5,320 ; 3,600) \cdot 10^{-3}\end{array}$ & $\begin{array}{l}(1,836 ; 1,836 ; 1,836) \\
(1,384 ; 1,000 ; 0,557) \cdot 10^{-2}\end{array}$ & $\begin{array}{l}(1,718 ; 1,717 ; 1,715) \\
(0,800 ; 0,800 ; 1,288) \cdot 10^{-8}\end{array}$ \\
\hline & $p r$ & $\begin{array}{l}n_{R}=1,2 \cdot n_{R}^{*} \\
n_{I}=1,0 \cdot n_{I}^{*}\end{array}$ & $\begin{array}{l}(1,836 ; 1,836 ; 1,836) \\
(8,500 ; 6,650 ; 4,500) \cdot 10^{-3}\end{array}$ & $\begin{array}{l}(1,836 ; 1,836 ; 1,836) \\
(1,730 ; 1,250 ; 0,696) \cdot 10^{-2}\end{array}$ & $\begin{array}{l}(1,718 ; 1,717 ; 1,715) \\
(1,000 ; 1,000 ; 1,610) \cdot 10^{-8}\end{array}$ \\
\hline & $p p$ & $\begin{array}{l}n_{R}=1,2 \cdot n_{R}^{*} \\
n_{I}=1,2 \cdot n_{I}^{*}\end{array}$ & $\begin{array}{l}(1,836 ; 1,836 ; 1,836) \\
(10,20 ; 7,980 ; 5,400) \cdot 10^{-3}\end{array}$ & $\begin{array}{l}(1,836 ; 1,836 ; 1,836) \\
(2,076 ; 1,500 ; 0,835) \cdot 10^{-2}\end{array}$ & $\begin{array}{l}(1,718 ; 1,717 ; 1,715) \\
(1,200 ; 1,200 ; 1,932) \cdot 10^{-8}\end{array}$ \\
\hline \multirow{3}{*}{ DN } & ref & $\rho^{*}\left(\mathrm{~kg} / \mathrm{m}^{3}\right)$ & $2,506 \cdot 10^{3}$ & $1,800 \cdot 10^{3}$ & $1,700 \cdot 10^{3}$ \\
\hline & $m$ & $\rho=0,8 \cdot \rho^{*}\left(\mathrm{~kg} / \mathrm{m}^{3}\right)$ & $2,005 \cdot 10^{3}$ & $1,440 \cdot 10^{3}$ & $1,360 \cdot 10^{3}$ \\
\hline & $p$ & $\rho=1,2 \cdot \rho^{*}\left(\mathrm{~kg} / \mathrm{m}^{3}\right)$ & $3,007 \cdot 10^{3}$ & $2,160 \cdot 10^{3}$ & $2,040 \cdot 10^{3}$ \\
\hline \multirow{3}{*}{ SH } & ref & $\chi^{*}$ & 1,000 & 1,000 & 1,000 \\
\hline & ext & $\begin{array}{l}\chi \text {-oblate } \\
\chi \text {-prolate }\end{array}$ & $\begin{array}{l}2,200 \\
4,500 \cdot 10^{-1}\end{array}$ & $\begin{array}{l}2,200 \\
4,500 \cdot 10^{-1}\end{array}$ & $\begin{array}{l}2,200 \\
4,500 \cdot 10^{-1}\end{array}$ \\
\hline & $\bmod$ & $\begin{array}{l}\chi \text {-oblate } \\
\chi \text {-prolate }\end{array}$ & $\begin{array}{l}1,600 \\
6,300 \cdot 10^{-1}\end{array}$ & $\begin{array}{l}1,600 \\
6,300 \cdot 10^{-1}\end{array}$ & $\begin{array}{l}1,600 \\
6,300 \cdot 10^{-1}\end{array}$ \\
\hline
\end{tabular}


Table 3: Results of the compatibility test on the best fit parameters, relative to the reference case and to the size distribution (SD), refractive index (RI), mass density (DN) and shape (SH) perturbation cases, for mineral dust (DU), organic carbon $(\mathrm{OC})$ and sulfate (SU). In the second column the perturbation cases are reported: the acronyms are explained in Table 2. The size distribution cases $\mathrm{mm}$ and $\mathrm{rm}$ and the refractive index cases $\mathrm{mm}, \mathrm{mr}$ and $\mathrm{mp}$ of mineral dust have been excluded from the fit analysis for the reasons explained in Section 4.

\begin{tabular}{|c|c|c|c|c|c|c|c|}
\hline \multirow{2}{*}{ cases } & \multicolumn{2}{|c|}{ DU } & \multicolumn{2}{c|}{ OC } & \multicolumn{2}{c|}{ SU } \\
\cline { 2 - 8 } & $s_{\text {test }}$ & $q_{\text {test }}$ & $s_{\text {test }}$ & $q_{\text {test }}$ & $s_{\text {test }}$ & $q_{\text {test }}$ \\
\hline \multicolumn{2}{|c|}{$r e f$} & 1,00 & 8,85 & 1,15 & 7,34 & 4,05 & 10,77 \\
\hline \multirow{5}{*}{ SD } & $m m$ & - & - & 1,39 & 10,65 & 2,86 & 27,59 \\
\cline { 2 - 8 } & $m r$ & 1,19 & 4,50 & 0,81 & 5,73 & 2,94 & 10,96 \\
\cline { 2 - 8 } & $m p$ & 1,03 & 13,93 & 2,22 & 7,49 & 6,25 & 21,70 \\
\cline { 2 - 8 } & $r m$ & - & - & 1,04 & 5,55 & 1,48 & 18,01 \\
\cline { 2 - 8 } & $r p$ & 0,93 & 16,71 & 2,47 & 7,03 & 6,94 & 25,98 \\
\cline { 2 - 8 } & $p m$ & 0,72 & 0,02 & 0,73 & 1,82 & 0,30 & 12,02 \\
\cline { 2 - 8 } & $p r$ & 0,91 & 12,23 & 1,43 & 8,26 & 4,95 & 11,96 \\
\cline { 2 - 8 } & $p p$ & 0,88 & 18,75 & 2,67 & 6,39 & 7,46 & 30,08 \\
\hline \multirow{5}{*}{ RI } & $m m$ & - & - & 0,54 & 7,16 & 0,20 & 59,77 \\
\cline { 2 - 8 } & $m r$ & - & - & 0,59 & 7,30 & 0,20 & 59,77 \\
\cline { 2 - 8 } & $m p$ & - & - & 0,63 & 7,44 & 0,20 & 59,77 \\
\cline { 2 - 8 } & $r m$ & 1,12 & 8,46 & 1,11 & 7,47 & 4,05 & 10,77 \\
\cline { 2 - 8 } & $r p$ & 0,90 & 9,22 & 1,19 & 7,22 & 4,05 & 10,77 \\
\cline { 2 - 8 } & $p m$ & 1,09 & 9,19 & 1,52 & 13,14 & 6,04 & 0,84 \\
\cline { 2 - 8 } & $p r$ & 0,98 & 9,60 & 1,56 & 13,02 & 6,04 & 0,84 \\
\cline { 2 - 8 } & $p p$ & 0,89 & 9,98 & 1,59 & 12,91 & 6,04 & 0,84 \\
\hline \multirow{2}{*}{$\mathbf{D N}$} & $m$ & 0,99 & 5,26 & 1,15 & 9,75 & 4,05 & 3,24 \\
\cline { 2 - 8 } & $p$ & 1,01 & 11,74 & 1,15 & 5,38 & 4,05 & 16,92 \\
\hline \multirow{2}{*}{ SH } & $e x t$ & 1,15 & 8,50 & 1,03 & 4,98 & 3,49 & 16,48 \\
\cline { 2 - 8 } & $m o d$ & 1,03 & 8,76 & 1,11 & 6,51 & 3,85 & 12,74 \\
\hline
\end{tabular}



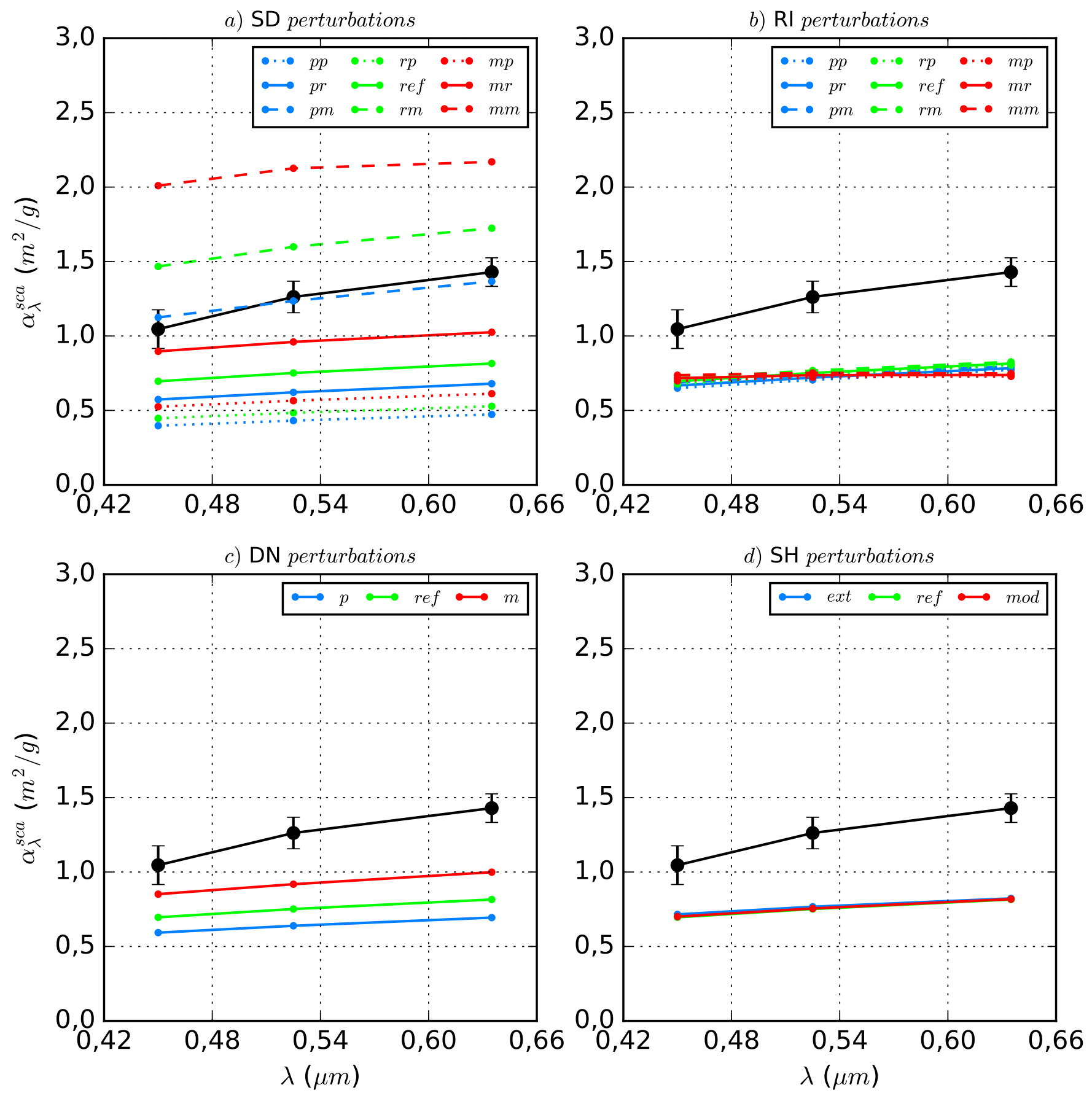

Figure 1: Spectral $\alpha_{\lambda}^{s c a}$, at the three wavelengths of the experiment, of mineral dust under a) size distribution (SD), b) refractive index (RI), c) mass density (DN) and d) shape (SH) perturbations. The black points are the observed values (mineral dust source) with their error bands (see Table 1) while the different colored lines are the code calculation results (see Table 2 for case acronyms). 

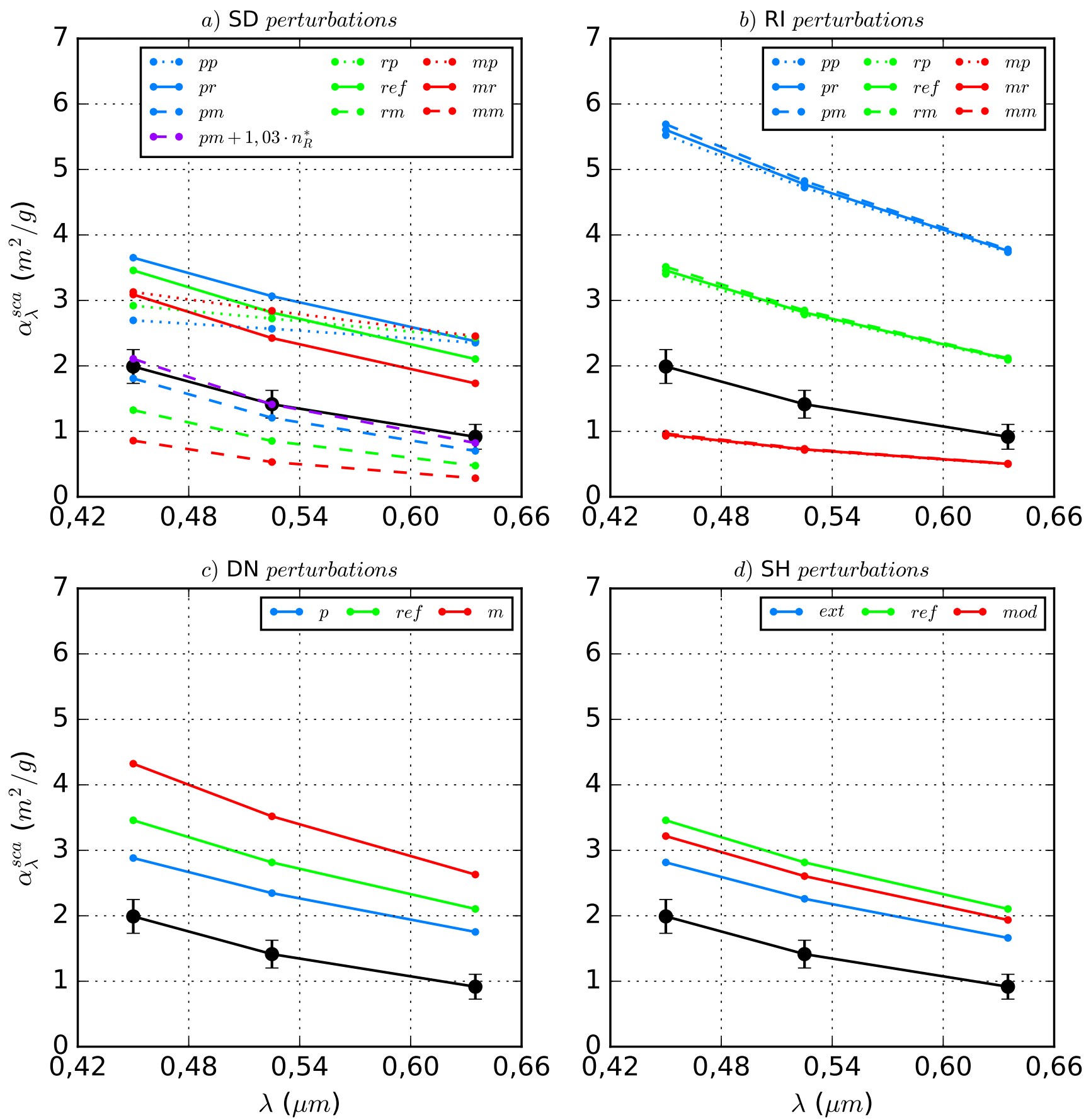

Figure 2: Spectral $\alpha_{\lambda}^{s c a}$, at the three wavelengths of the experiment, of organic carbon under a) size distribution (SD), b) refractive index (RI), c) mass density (DN) and d) shape (SH) perturbations. The black points are the observed values (aged organics source) with their error bands (see Table 1) while the different colored lines are the code calculation results (see Table 2 for case acronyms). 

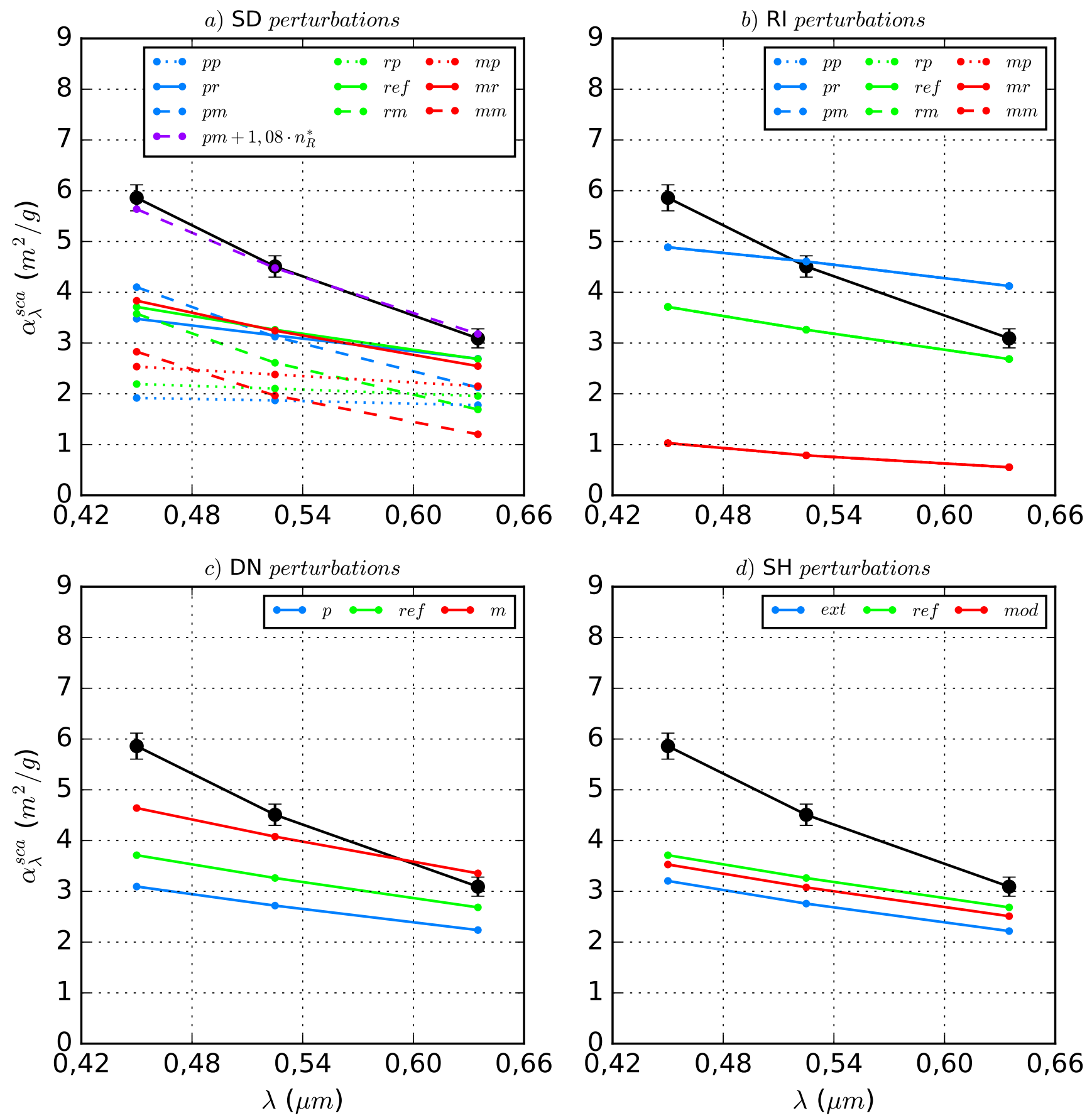

Figure 3: Spectral $\alpha_{\lambda}^{s c a}$, at the three wavelengths of the experiment, of sulfate under a) size distribution (SD), b) refractive index (RI), c) mass density (DN) and d) shape (SH) perturbations. The black points are the observed values (ammonium sulfate source) with their error bands (see Table 1) while the different colored lines are the code calculation results (see Table 2 for case acronyms). 